HID 40 (2013)

\title{
LA MEMORIA ESCRITA DE LA CASA DE GRANADA: EL ARCHIVO DEL MARQUESADO DE CAMPOTÉJAR (S. XV-1643) $)^{1}$
}

THE WRITTEN MEMORY OF THE HOUSE OF GRANADA: THE ARCHIVE OF THE MARQUESADO DE CAMPOTÉJAR (15 ${ }^{\mathrm{TH}}$ CENTURY-1643)

\author{
José Antonio García LuJÁN \\ Universidad de Córdoba \\ ca1galuj@uco.es
}

RESUMEN: A partir del inventario judicial de bienes realizado en 1643 al morir don Pedro de Granada Venegas Manrique de Mendoza, primer marqués de Campotéjar, se analiza la historia del archivo de la Casa de Granada, su organización y los documentos que contenía, en su mayoría conservados durante siglos en la Casa de los Tiros de Granada y trasladados a principios del siglo XX a Italia, donde hoy se hallan.

Palabras ClaVe: Archivos nobiliarios, linaje Granada Venegas, Historia de Granada siglos XV-XVII.

ABSTRACT: In 1643, following the death of "Don Pedro de Granada Venegas Manrique de Mendoza", the first "Marqués de Campotéjar", a legal property inventory was carried out. The history of the archive of the House of Granada was analyzed, as well as its organization and documents contained within, kept for centuries in "Casa de los Tiros" in Granada and most of which was transferred at the beginning of the twentieth century to Italy, where they are still today.

KEYWORDS: Nobility archives, Lineage Granada Venegas, History of Granada 15 th-17th centuries.

1. Abreviaturas utilizadas. $\mathrm{AHN}=$ Archivo Histórico Nacional; $\mathrm{AMCO}=$ Archivo del Marqués de Corvera. 


\section{Historia DEL ARCHIVO}

El tronco que da unidad al Archivo del Marquesado de Campotéjar es el linaje Granada Venegas, sobre el que conviene precisar que primero fue estirpe AlNayyar por sus titulares Sidi Yahya al-Nayyar y Ali Omar ibn Nazar -don Pedro de Granada y don Alonso Venegas a partir de su conversión- y posteriormente dinastía Granada Venegas por imposición de este último, al fundar mayorazgo en $1533^{2}$, a los sucesores en el mismo de tomar ambos apellidos.

Archivo, pues, personal de los titulares de la Casa de Granada, familiar por la producción, transmisión y conservación de documentos de ascendientes, descendientes y colaterales del linaje, y nobiliario: nazarí en su origen, pues a la alta aristocracia granadina, con estrechos vínculos con la dinastía reinante, pertenecieron sus dos primeros titulares, y castellano a partir de 1632 en que el quinto señor de la Casa don Pedro de Granada Venegas Manrique de Mendoza alcanza el título de vizconde de Miravalles y marqués de Campotéjar en $1643^{3}$.

Los fondos más antiguos hubieron de custodiarse en el Palacio de los Infantes de Granada, residencia de los Al-Nayyares, y a partir de 1540 en el palacio renacentista de la Casa de los Tiros, morada del cabeza del mayorazgo y Casa de Granada que desplaza a aquella, hasta que en 1619 don Pedro de Granada Venegas Manrique de Mendoza se traslada a Madrid llevando consigo el archivo. Inventariados sus papeles por orden judicial al fallecer en 1643, permanecieron en la Villa y Corte mientras se resolvía la compleja herencia que dejó, volviendo a Granada en 1648 con don Juan de Granada Venegas Ochoa sucesor en el mayorazgo y Casa como tercer marqués de Campotéjar.

Un archivo vivo a lo largo de los siglos, desde el último cuarto del siglo XV a principios del XX, pues extinguida la línea primogénita de varonía en 1660 sus fondos serán incrementados sucesivamente por los linajes Lomellini, Grimaldi y Pallavicini hasta que en 1922 devino en archivo cerrado e histórico. Este importante acervo documental fue trasladado desde Granada a Italia en 1928 y los 60 legajos que se afirma lo forman agregados a los archivos Durazzo Pallavicini, sin que hasta la fecha hayan sido inventariados, catalogados o descritos. Por ello no es posible comparar su contenido con el de los dos inventarios de que disponemos, uno amplio de 1643, ahora objeto de estudio, y otro más breve de $1682^{4}$, únicos medios de conocer la calidad y cantidad de la documentación que contenía y contrastarla con la que se ha conservado actualmente; sin peligro de desaparecer o dis-

2. J.A. GARCÍA LUJÁN. "Genealogía del linaje Granada Venegas desde Yusuf IV, rey de Granada (1432), hasta la extinción de la varonía del linaje (1660)”, en J.A. GARCÍA LUJÁN. (ed.) Nobleza y Monarquía. Los linajes nobiliarios en el Reino de Granada, siglos XV-XIX. El linaje Granada Venegas, marqueses de Campotéjar, Huéscar, 2010, p. 31.

3. J.A. GARCÍA LUJÁN. "Don Pedro de Granada Venegas, I marqués de Campotéjar (1643), de Campo Rey y Vizconde de Miravalles (1632), en VII Simposio Internacional de Mudejarismo. De mudéjares a moriscos: una conversión forzada, Teruel, 2002, vol. II, pp. 721-740.

4. C. CALERO PALACIOS, R.G. PEINADO SANTAELlA. "Fuentes para el estudio de la nobleza y los señoríos del Reino de Granada: el inventario del Archivo del Marquesado de Campotéjar (1682)", Revista del Centro de Estudios Históricos de Granada y su Reino, 2a época, 1 (1987), pp. 239-260. 
persarse, permanece desconocida por su inaccesibilidad ${ }^{5}$ y constituye la memoria escrita de los diversos linajes que se sucedieron en la Casa de Granada.

El Inventario de 1643 recoge 600 asientos archivísticos, cuyo número real de documentos es exponencialmente mayor, frente a solo 150 anotaciones en el Inventario de 1682. Sorprende tan gran diferencia en tan poco espacio de tiempo, aun considerando las pérdidas que pudo haber y la apropiación selectiva de documentos por doña Gertrudis de Granada Venegas de la Cueva, viuda del tercer marqués de Campotéjar, al fallecer éste en 1660 y suceder mediante pleito de tenuta en el Estado, título y archivo de Campotéjar don Pedro Lomellini Pavesi. No de otra forma se explica que documentos referidos en el Inventario de 1643, y otros que no lo son pero atinentes a la línea de primogenitura Granada Venegas, hayan estado o estén hoy en el Archivo del Marqués de Corvera, llegados a través del vizcondado de Rías ${ }^{6}$, cuyo primer poseedor don Juan Suárez de Toledo Obregón había casado en 1652 con doña Juana de la Cueva Granada Venegas, hija de doña Gertrudis. Ésta y su yerno tomaron los documentos que les interesaban como herederos de los Granada Venegas y en consecuencia gozar de los privilegios y franquezas que les habían sido otorgadas ${ }^{7}$, ya que no parece plausible que compraran o adquirieran por otra vía los papeles de una Casa nobiliaria a la que pertenecían y en cierto sentido era la suya propia ${ }^{8}$.

En concreto y a modo de ejemplo, los documentos citados en el Inventario con los números $65,68,69,70,71,72,73,74,75,76,77,78,79,80,81,83,84,85,86$, $87,88,93,95,97,100,101,102,103,104,106,107,109,114,115,116,117,118$, $121,122,124,129,150,331$, más otros diplomas no mencionados en el mismo, estuvieron o están actualmente en el Archivo del Marqués de Corvera. Requisado en 1936 por la Junta de Defensa del Tesoro Artístico Nacional, fue devuelto a su propietario años después, aunque algunos documentos quedaron en el Archivo Histórico Nacional, Sección Diversos. Títulos y Familias, Marquesado de Astorga y otros se hallan en el Archivo del Ministerio de Justicia, títulos de Duque de Çidi Hiaya ${ }^{9}$ y Marqués de Campotéjar, presentados para su rehabilitación o sucesión en la primera mitad del siglo XX.

5. Se tiene noticia de que hace unos años un becario de la Universidad de Granada ha accedido, pero se desconocen los resultados. Mesa de debate celebrada en Granada el 23 de febrero de 2007 en la sede del Diario La Opinión de Granada.

6. Título creado en 1688, se incorporó a la Casa de Corvera al matrimoniar don Rafael María de Bustos Llamas con doña María Antonia Sagade Bogueiro Valderrama, VII vizcondesa de Rías J.A. GARCÍA LUJÁN. Genealogía y heráldica nobiliarias. La Casa Ducal de Pastrana, Córdoba, 2004, II.2. Título de Marqués de Corvera, II.3. Título de Vizconde de Rías.

7. Así, entre otros documentos, la Carta de privilegio y confirmación de 1629, que en extenso cuaderno recoge todas las confirmaciones de privilegios de monarcas anteriores hasta don Pedro de Granada, primer titular de la Casa. Guardada en el Archivo de los Vizcondes de Rías pasó al de Corvera y hoy está en AHN Nobleza, Diversos. Títulos y Familias.

8. Como línea segundogénita iniciada por don García de Granada Venegas Quesada, hijo de don Alonso Venegas y doña María de Quesada Acuña. Por su testamento otorgado en 1666 fundó mayorazgo en esta hija habida en su primer matrimonio con don Rodrigo de la Cueva Benavides, señor de Gorafe y Alamedilla.

9. Así los asientos 146 y 148 del Inventario de 1643 son los docs. 54 y 23 en este título. 
En virtud del acuerdo transaccional ${ }^{10}$ entre el Estado español y don Giacomo Filippo Durazzo Pallavicini, marqués de Campotéjar, en 1922 se hizo entrega al Patronato del Generalife del palacio Casa de los Tiros y unos 250 documentos $^{11}$, depositados hoy en su no totalidad en el Museo Casa de los Tiros y en el Archivo de la Alhambra. Algunos de ellos se relacionan en el Inventario de 1643 y de otros se infiere que estaban en el archivo del marquesado de Campotéjar en esa fecha. Décadas después, en 1990, el Banco Meridional donó al Patronato de la Alhambra y Generalife 43 documentos adquiridos en la Casa de Subastas Sotheby's, cronológicamente de 1492 a 1792, en su mayor parte originales ${ }^{12}$, que en parte se corresponden con los documentos donados en 1922.

Recientemente, a partir de la solicitud de la Fundación Garnata-Medievo Escrito Andalusí, el Ayuntamiento de Granada en pleno ${ }^{13}$ acordó solicitar a la Consejería de Cultura de la Junta de Andalucía se iniciaran los trámites a fin de gestionar el retorno de los fondos documentales granadinos que obran en poder de la Casa Durazzo Pallavicini, esto es, el Archivo del Marquesado de Campotéjar expatriado en 1928. En su respuesta, la Jefatura del Servicio de Archivos emitió informe ${ }^{14}$ manifestando que en 1922 no existía normativa sobre protección y exportación del patrimonio documental, que son bienes de titularidad privada en el extranjero que salieron del país legalmente, y que la única posibilidad de retorno de dichos fondos pasa por la necesaria colaboración y voluntad de sus legítimos propietarios, materializada mediante una oferta de venta con las condiciones y requisitos legalmente exigidos. Entre ellos, sería fundamental que se acompañase un instrumento de descripción del fondo que determine su contenido y naturaleza, ya que hasta el momento no se ha publicado ninguno que permita conocer su volumen y alcance, oferta que en todo caso debe contar con su conformidad a la legislación italiana en la materia. Además de estas cuestiones legales, desde el punto de vista económico habría que disponer de la suficiente dotación presupuestaria para atender la oferta. Y en conclusión, se aconseja poseer un instrumento de descripción del Archivo y,

10. 6 de septiembre de 1921, su punto 5 establecía que: "El Marqués de Campotéjar cederá gratuitamente al Estado Español aquellos documentos de su archivo que se refieran al Generalife y todos aquellos que, a juicio de la representación de la Casa, no fuesen de interés exclusivo para ella y pudieran ser útiles para la Historia o el Arte españoles".

11. 19 del siglo XV, 98 del XVI, 48 del XVII, 51 del XVIII, 19 del XIX, 3 árabes y otros tantos sin fecha. Delegación de Hacienda de Granada. Administración de Propiedades del Estado, caja 3676, expediente 35-15. Extraña que M. GARRIDO ATIENZA no consultara los fondos para su monografía Las capitulaciones para la entrega de Granada, Granada, 1910, y que R. de P. Valladar, lo hiciera en corta medida en sus artículos. Su acceso era posible, pues por encargo de don Alfonso de Bustos y Bustos, VIII marqués de Corvera, el archivero de Hacienda don Pedro Gan le transcribió documentos y el notario don Antonio García Trevijano dio fe de otros, que fueron aportados en la rehabilitación de diversos títulos nobiliarios. J.A. GARCÍA LUJÁN. Estudio introductorio a la edición facsímil de A. DE BUSTOS Y BUSTOS. Marqués de Corvera, Guerra y sitio de Baza en el siglo XV y Breve estudio del tratado de don Fernando el Católico, rey de Castilla y Aragón, con Yahia Alnayar, antes príncipe Cidi Hiaya, en lo que se refiere a la Grandeza a favor del mismo reconocida. Granada, 2008, pp. XVII-XXV.

12. Archivo de la Alhambra, I-424/19 (archivo Intermedio).

13. Sesión ordinaria de 26 de enero de 2007.

14. 5 de noviembre de 2007, r. s. 1341 . 
a la luz de su análisis y valoración técnica, una vez comprobado su contenido e interés, intentar realizar las gestiones oportunas para, cuando menos, su regreso "virtual" a Andalucía, mediante su reproducción en soporte digital. Solución que parece más idónea y viable, tanto desde el punto de vista económico como legal.

\section{El ARCHIVO. CONTINENTES, CONJUNTOS Y UNIDADES DOCUMENTALES. ORGANIZACIÓN}

El Inventario de los "papeles", nunca se menciona la palabra archivo, fue realizado entre el 3 y 5 de marzo de 1643 en presencia del escribano real Antonio de Carvajal, que por su asistencia al inventario, tasación y almoneda de los bienes que quedaron por muerte del primer marqués de Campotéjar, poderes, fe de ellos y otros autos tocantes a la partición de herederos cobró 500 reales, la mitad a cuenta. No hay referencia a inventarios previos a este judicial.

El número de los asientos se indica en el margen izquierdo con numeración arábiga, pero no de modo sistemático, pues en numerosas ocasiones un guarismo abarca varias anotaciones, motivo por el que en la transcripción del inventario hemos asignado una cifra propia a cada conjunto y unidad documental.

La escrituración de los asientos sigue un orden a partir de las once unidades de instalación, muebles-archivo en su mayoría, de diversa factura, materia y tamaño, que guardaban los documentos encuadernados, enlegajados o apilados unos sobre otros. Para ser precisos: un escritorio de pino con seis cajones y un cajoncillo; un escritorio con siete cajones, del que no se describen los papeles que hubiera en el tercero; un escritorio de nogal embutido, esto es, incrustado de piezas de la misma u otras materias de distinto color formando dibujos, con nueve cajones; un escritorio de ébano y marfil de doce cajones con una alacena, de los cuales no se inventariaron, si los había, los documentos de los cajones tercero y duodécimo, y del noveno se declara que "no uvo papeles en él"; un escritorio de ébano y marfil con once gavetas, de las cuales no se enumeran los documentos de las gavetas novena y décima; un escritorio de pino de cuatro cajones; un escritorio de pino con ocho cajones; un escritorio de pino de siete cajones, cuyas gavetas quinta a séptima no se puntualiza si tenían o no documentos, y en caso de haberlos no fueron inventariados; un arca grande de pino; una arquilla de pino y una arquilla pequeña.

No se menciona si este mobiliario ${ }^{15}$ tenía puertas, cerraduras, llaves, número y personas que las poseían. Es admisible que tuviera al menos una llave, como es habitual $^{16}$, que estaría en poder de su propietario y en su ausencia en manos de una

15. Es larga la relación de muebles de madera y ébano tasados por el ensamblador Andrés León: escritorios de ébano, carey y bronce la guarnición, dos escritorios de ébano y marfil, "ambos en el aposento de don Pedro", escritorios de ébano, carey y palo santo, bufetes grandes y medianos, de caoba o nogal, con o sin cajones, dos compañeros en la sala alta de recibir, dos bufetillos para escrituras, escritorio de papeles cubierto con badana negra, estante para papeles, escritorios de pino, etc.

16. Así, tenían sus cerraduras y llaves, dos cofres de viaje, dos arcas vareteadas de hierro, dos escritorios contadorcillos, arcas de pino, etc. 
persona de su plena confianza. La afirmación previa al inventariado de los papeles "abriose" un escritorio/arca/arquilla y acabado el mismo de que "se cerró", evidencia que alguna llave tenía. Tampoco se precisa si este mobiliario estaba en una sola habitación-archivo independiente o en varias salas de la residencia madrileña de don Pedro de Granada, como es más probable ${ }^{17}$, ni que los cajones estuvieran numerados o rotulados. Desconocemos si el dueño realizó en su archivo nobiliario lo que por manda testamentaria dispuso para salvaguarda de la documentación de la Obra Pía que instituyó: que en la Casa de los Tiros de Granada, en la parte que pareciera más a propósito a los testamentarios, se creara un archivo con sus puertas fuertes con tres llaves, donde se pusieran todos los papeles de la Obra, con su inventario en un libro de pergamino para que siempre constase cuáles eran, no pudiendo sacar ni meter documento alguno sin que previamente se asentara el motivo en el inventario, firmado por las tres personas que tuvieran las llaves ${ }^{18}$.

Los 600 asientos del Inventario corresponden a otras tantas unidades archivísticas, compuestas por unas pocas o numerosas escrituras, y documentales, que no se corresponden con el número total de documentos existentes en el Archivo, muy superior a esa cantidad, ya que en un mismo registro se engloban varios sin describirlos individualmente, y en muchos casos se mencionan legajos groso modo sin especificar el número de piezas que los integran. Las más de las veces se indica la variada tipología diplomática de las escrituras inventariadas y su tradición documental -original, traslado autorizado, copia simple, etc.-, y pocas la fecha, casi exclusivamente en los legajos de cartas -misivas, personales, de cuentas, etc.agrupadas por años.

Estas unidades archivísticas y documentales no estaban reconocidas exteriormente de modo sistemático y en ningún caso se dice que poseyeran alguna signatura o número individual para una rápida localización. En ocasiones se copia literalmente el breve texto identificativo del contenido, que va en una cédula exterior pegada (nn. 1, 65, 95, 106, 134, 145,) o directamente en la cubierta o envoltura, de pergamino, papel, papel de estraza (nn.. 8, 159, 163,164, 175, 177, 196, 203, 212, 214, 215, 244, 245, 261, 489, 494, 524).

Relativa es la ordenación de los documentos, archivados por personas y asuntos, pero sin una aplicación sistemática, casi absoluta en los relativos a los titulares de la Casa, pero lo habitual es la mezcla de escrituras de diversas materias que no guardan relación entre sí, por ejemplo, entre otros muchos, los asientos nn. 322-324. El estado de conservación era bueno, pues solo en un caso se especifica que los papeles están "agujerados" (n. 278).

Como elemento supremo de la validación documental y de la confidencialidad de su contenido, entre los papeles del archivo se hallaban dos sellos de don Pedro de Granada con sus armas (n. 332).

17. Un arca blanca, junto con otras en la recámara, contenía unas botas de camino, unas alforjas y unos atados de papeles; tres arcas viejas contenían papeles y libros; en un cofre pequeño había papeles, y un estante era para papeles.

18. El arcipreste de la iglesia del Sagrario de Granada, el patrono de la Obra Pía y una tercera persona. 
De distinta naturaleza es la agrupación física de los documentos.

Por su afinidad temática y evitar su disgregación, una bolsa de lienzo contenía los títulos del mayorazgo fundado por el comendador Gil Vázquez Rengifo (n. 337), en un envoltorio de papeles con un cuero estaban los tocantes a la antigüedad de la Casa de Granada (n. 579), en tanto que sendos cuadernos recogían la sucesión de Gil González de Ávila (n. 203), la Guerra de Granada (n. 205), el testamento y codicilos del emperador Carlos V (n. 581), y monográficamente un proceso de ejecución (n. 206) y cobro de rentas (n. 279).

En contrapunto a los documentos sueltos y a los muy numerosos legajos, con el término de atado se menciona la agrupación documental de varios memoriales, un testamento y cartas de pago (n. 226).

Los atados de papeles, no siempre de una misma materia, según su menor o mayor número, son denominados legajillos (nn. 212, 313, 318, 320) y legajos. Éstos son la agrupación física mayoritaria y su descripción oscila de la concisa "legajo"19 con la/s materia/s de que tratan -(nn. 166, 178, 179, 194, 209, 210, 213, 219, 246, 248, 250, 251-254, 256, 257,259, 260, 263-277, 280, 282-285, 287-289, 291-295, 297-305, 319, 323-325, 327-330, 333-335, 338, 339, 341-344, 346-348, $351,356,359,365,369,372-375,378,380,382-384,390,396,405,407,410$, 416, 423, 427, 435-441, 450, 451, 457, 459, 465, 466, 468, 469, 494, 497, 500-503, 506-511, 517-519, 528-530, 532-536, 540-543, 548, 549, 559, 562, 564-568, 584, 592, 594, 595, 597-599)-, a otras más amplias señalando tamaño y si están doblados -grande (n. 515), en folio (nn. 193, 195, 486), doblados (nn. 167, 171, 290, $314,316,317,386,387,414$ ), doblados, en cuarto, (nn. 162, 165, 183, 255, 262, $322,326,345,368,385,409,491$ ), doblado, en folio (n. 493)-, atados y con qué -atados (nn. 176, 182, 261, 499, 596), atados, en cuarto (nn. 180, 181, 216, 218, 220, 236, 238-240, 247, 249, 371, 488-490, 492, 516, 527), cubiertos con papel de estraza (nn. 238, 336), atados, en folio (nn. 185, 198, 242, 310), de a folio y de a cuarto, atados todos juntos (n. 296), doblados, atados con una cuerda (n. 160), doblados, en cuarto, atados con una "trancadera" (n. 235), atados con un cordón de seda negra (n. 340)-.

Y también la cubierta de materia innominada, pergamino o papel con texto que describe su contenido: debajo de una cubierta que dice "perpetuación de la veinte y quatría de Granada", doblados, en cuarto, con un pergamino por cubierta donde dice "títulos de Santa Polonia, Cordovilla y San Pedro de la Breña y fuente de Restával y de las ventas camino de Jayena y Prado Redondo, casa de Almuñécar y rejimiento perpetuo" (n. 159), en folio, que dice "linaje de los Reyes de Granada" (n. 163), en cuarto y en la cubierta "linaje de Granada en Portugal" (n. 164), doblado que dice "papeles tocantes a la hacienda de Madrid y a los quinientos maravedís de censo que estavan sobre la güerta que trocó don Pedro de Porras" (n. 172), de a folio, entremetidos otros de a cuarto, atado con hilo de cartas, y en la cubierta "papeles tocantes al pleito con el señor don Fernando, chantre de Cuenca" (n. 175), atado y en la cubierta "raçón del hacienda que quedó en Granada a

19. "Papeles" en (nn. 281, 422). 
principio de diziembre de seiscientos y diez y nueve" (n. 177), en folio, que dice "breve relaçión del pleito de Güetor" (n. 196), atados, en cuarto, que dice "legajo de papeles tocantes a Almuñécar" (n. 214), atado, en cuarto, con cubierta de papel que dice "cartas de pago y testimonios de la quenta que dio Alonso Martínez de Piqueras el año de mill y seiscientos y treinta y cinco" (n. 215), atado, en cuarto, que dice "relación para el señor don Fernando de Villafañe tocante al hacienda de Madrid conforme al testamento de la señora Mencía Ortiz” (n. 489).

Un legajo, atado, presentaba la forma de rollo por ser pieza de auto, concretamente dos requisitorias judiciales (n. 560).

Con el nombre de libros, seis unidades archivísticas con cubierta de becerro, en ellas unos documentos sueltos y otros cosidos, agrupaban los pertenecientes a los titulares de la Casa de Granada, identificados con una cédula, papel, exterior pegada: "don Pedro de Granada quinto de la Cassa, primero marqués de Campotéjar” (nn. 1-64), “don Alonso de Granada Venegas 4 de la Cassa” (nn. 65-94), "don Pedro de Granada tercero de la Casa" (nn. 95-105), "de don Alonso de Granada segundo de la Cassa” (nn. 106-133), "don Pedro de Granada el primero" (nn. 134-144), "don Pedro de Granada primero de antes de su santa conversión" (nn. 145-151). Aunque mezclados con ellos hay documentos de familiares de los titulares, como es el caso, entre otros, de la certificación de caballero de Santiago de don Diego de Granada Venegas Manrique (n. 42), las informaciones sobre la limpieza de sangre de Diego Francos (n. 92), el título de hábito militar de don Egas de Mendoza (n. 99), el testamento de doña Juana de Mendoza (n. 112), o la carta del infante don Alonso, intitulándose rey de Castilla, al infante Ibn Selim (n. 146). Y en algunos casos, escrituras de un titular se hallan entre las de otro, así la merced a don Pedro de Granada de llevar escolta personal está entre las de don Alonso de Granada Venegas (n. 89).

La voz libro sin mayor precisión, salvo la mención del tipo de documentación que contiene, se usa en los asientos (nn. 479, 480, 484, 577, 578, 600), pero en otros se detalla su forma, tamaño, atadura y con qué, si están o no protegidos con cubierta o presuntamente encuadernados y con qué materia, y texto descriptivo del contenido: libro de pergamino (nn. 155, 570-572), libro de pergamino, doblado (n. 309), libro a lo largo (nn. 211, 575), libro con cubierta de pergamino (n. 234), libro con cubierta de pergamino que dice "carta de venta de las tierras que compró el señor don Pedro de Granada en el pago de Piçarrama” (n. 230), libro de pergamino, la cubierta dice "escritura de censo que paga don Rodrigo de Herrera de mil ducados de principal" (n. 231), libro, atado con una "trancadera" (n. 233), libro con pergamino, de folio (n. 232), libro, en folio, de pergamino (nn. 237, 241, 312), libro, de folio, con su pergamino, que dice "Jeneralife y los títulos del alcaídia y perpetuación y otros papeles tocantes a ella" (n. 173), libro de a cuarto (n. 576), libro, de cuarto, de pergamino, con una cinta de cuero (n. 485), libro grande, de a folio (n. 569), libro grande, de pergamino, con dos botones (n. 573), libro viejo, largo (n. 574), librillo de quince hojas escritas (n. 221).

En contadas ocasiones se afirma que es pergamino "con vuelta" o pergamino "vuelto", que quizás pueda interpretarse, en acepción recogida por el Diccionario 
de la Lengua Española de la Real Academia, como una breve y personal diligencia escrita para el reconocimiento de su contenido: libro, de folio, con pergamino con vuelta que dice: "título de los cortijos de Santa Polonia" (n. 158), dos libros de pergamino vuelto que dice "filiación del muy ilustre señor don Pedro de Granada" (nn. 198, 199); aunque en dos registros no se dice el texto: libro, de folio, con pergamino vuelto (n. 174), librillo, en cuarto, de pergamino vuelto (n. 498). No obstante, esta expresión también podría referirse a una forma de encuadernación en la que la cubierta de pergamino, más larga por un lado que por otro, se dobla a modo de sobre para proteger lo que engloba ${ }^{20}$.

La encuadernación en su sentido literal, no como simple cubierta protectora de los documentos, se cita expresamente en unos pocos asientos: memorial encuadernado en pergamino (n. 186), libro encuadernado, con cintas (nn. 192, 197), libro encuadernado en pergamino (nn. 190, 191), tres libros encuadernados con cubiertas de badana, con letras doradas encima que dice "previlejio de la villa de Jayena" (n. 227), "previlejio de la villa de Campotéjar" (n. 228), y el tercero con un sello de plomo pendiente (n. 229), libro encuadernado en tablas de becerro (n. 308), libros largos, encuadernados, y en uno ellos dice "memoria de los pleitos" (nn. 524-526).

En un libro de tablas, esto es, encuadernado en madera, con un sello de plomo, se protegían "las entregas que se hicieron por los reyes moros de la ciudad de Granada" (n. 152), confusa reseña que debe corresponder al privilegio rodado de las Capitulaciones de Granada, donado en 1908 al Ayuntamiento de la ciudad por don Alfonso de Bustos y Bustos, VIII marqués de Corvera.

\section{LOS DOCUMENTOS}

Cuantiosos en número y asuntos, pero parcos en contenido por su propia naturaleza de inventario, no es fácil estructurar la dispersa información que proporcionan los 600 registros para encarnar la estructura ósea esquemática de los asientos inventariados. Helos aquí sistematizados.

1. Genealogía y escudos de armas. Mayorazgos y títulos nobiliarios. Pleitos sobre mayorazgos y títulos.

Sin duda los registros de materia genealógica son fuente de información decisiva para conocer los orígenes de este linaje. De la antigüedad de la Casa y estirpe Granada $^{21}$ dan razón de forma general los asientos (nn. 90, 579, 592), en tanto que otros tratan de modo específico sobre la progenie de los reyes de Granada (n. 163), la filiación de don Pedro de Granada antes de su conversión (nn. 198, 199), expresada asimismo en su contrato de matrimonio con Cetti Meriem Venegas (n. 148), y los

20. Agradezco a Alicia Córdoba Deorador, directora del Archivo Histórico Provincial de Córdoba, su opinión sobre este vocablo "con vuelta", "vuelto" referido al pergamino.

21. J.A. GARCÍA LUJÁN. "Genealogía del linaje Granada Venegas ..., pp. 13-43. 
servicios de don Pedro de Granada Venegas Manrique de Mendoza con la extraña inscripción en la cubierta del legajo "linaje de Granada en Portugal" (n. 164). Dinastía que es representada en un árbol genealógico, en papel y gran tamaño, con óvalos describiendo la progenie familiar (n. 504), todo lo cual prueba y hace perdurable su memoria.

Los Rengifo abulenses (nn. 201-203) emparentaron con los Granada al contraer nupcias don Pedro de Granada Venegas Mendoza con doña María Rengifo Dávila, hija del comendador Gil Vázquez Rengifo. Éste en su matrimonio con doña María Guillén recibió 1.300 ducados a cuenta de la dote (n. 395), y ambos otorgaron mayorazgo en 1535 a favor de su primogénita (n. 337). Constructor del palacio Casa de los Tiros en Granada, donde otorgó testamento y codicilo (n. 204), es la Cuadra Dorada la sala más noble e interesante, también llamada de los Reyes por los retratos tallados y dorados en su techo artesonado, acompañados de una leyenda que rememora sus hazañas, de la que son traslados los (nn. 377, 385). Ciertamente, especial interés debe tener un cuaderno sobre la Guerra de Granada (n. 205) en la que su progenitor Juan Vázquez Rengifo fue héroe en el asedio de Málaga y muerto en la Vega.

Con doña María Rengifo Dávila se incorporaron al archivo los documentos de sus abuelos Gómez Guillén y Mencía Ortiz. Tesorero de los Reyes Católicos y regidor de Madrid vivía en la calle del Arenal (n. 482), erigió capilla funeraria propia en la iglesia de San Ginés (n. 481), constituyó un notable patrimonio, en particular huertas en el arroyo del valle de Atocha (nn. 483, 485, 488), gravadas con diversos censos perpetuos (n. 479), y fundo mayorazgo en su testamento (n. 480). Las particiones de bienes entre sus herederos no fueron pacificas, en particular entre Mencía Ortiz y su hija mayor doña María Guillén por las citadas huertas (nn. 486, 487), que requirió carta ejecutoria de la Chancillería de Valladolid (n. 476), y tampoco fue serena la partición y transacción de Mencía Ortiz con los hijos habidos en sus dos matrimonios (nn. 477, 484, 489). Esta hacienda madrileña (n. 172) pasó a dona Aldonza Rengifo y marido don Ginés de Carranza, que la pusieron en arrendamiento (nn. 325, 490), aunque se vendió alguna de las huertas (n. 478).

Junto con un importante patrimonio urbano, rústico y dinerario, doña María Rengifo Dávila aporto sangre judía conversa al linaje Granada, pues su abuela Mencía Ortiz tuvo unos hermanos llamados Francisco, Tomás y Pedro Franco que habían sido tenedores de bastimentos en Madrid y a la madre de todos ellos la llamaban la Franca vieja, mujer de Diego Franco, y la propia Mencía Ortiz siendo moza llevó desde su casa las tablas de pescado para los bastimentos de la villa. En consecuencia, no se les tenía a María Guillén y a los Franco por gente limpia de mancha, muy al contrario eran conversos que habían realizado oficios bajos como vender pescado y otros semejantes, y "de confesos muy bajos". Para mayor abundamiento, a otros familiares de los Franco se les había hecho información de sangre al aspirar a ciertos cargos, que no obtuvieron por no ser limpios, como fue el caso de Juan Franco, provisor en Zamora en 1569, hijo de Pedro Franco y sobrino de Mencía Ortiz, al que en tiempo del arzobispo don Juan Tavera se le hizo pesquisa para nombrarlo vicario general de la diócesis de Toledo, cargo que no se le 
dio por probar el Santo Oficio que era converso ${ }^{22}$. De ahí que en el archivo hubiera una memoria con las informaciones que se presentaron para verificar la limpieza de Diego Franco (n. 92), así como cédula del Emperador sobre la consulta que le hizo el Santo Oficio (n. 131) y auto de este (n. 133) sobre fray Felipe de Mendoza, profeso en la Orden de Santo Domingo y compañero de fray Luis de Granada, que quizás llegó a ser ministro de la Suprema al exhortar el monarca al cardenal arzobispo de Sevilla e inquisidor general Alonso Manrique de Lara no fuese impedimento su ascendencia musulmana para serlo. Mácula islámica, que llevaría años después al Consejo de la Inquisición a emitir un auto sobre la calidad de don Pedro de Granada Venegas Manrique de Mendoza y miembros de su Casa (n. 43).

Los escudos de armas como elementos externos a la persona de expresión de nobleza pronto fueron ostentados por don Pedro de Granada y don Alonso Venegas en premio a sus servicios en la Guerra de Granada, en cuyo transcurso el segundo obtuvo sendas victorias sobre Adra y en la Torre del Romaní, siéndole concedido por los monarcas que pudiera mostrar por blasón las siete banderas tomadas en este lugar de la Vega (n. 106) y la roja ganada en aquella villa. Igualmente, en 1503, Isabel I señalaba a don Pedro de Granada las armas que podía exhibir, consistentes en cinco granadas de oro, abiertas, puestas en sotuer en un escudo azur con su coronel (n. 142) ${ }^{23}$.

Cuatro son los mayorazgos de la Casa de Granada ${ }^{24}$ : el instituido por don Alonso Venegas en 1533 (nn. 155, 200), el fundado por Gil Vázquez Rengifo y su mujer doña María Guillén (n. 156) como bienes dotales de su primogénita María Rengifo Dávila al casar con don Pedro de Granada Venegas Mendoza en 1535, el otorgado por aquella a favor de su nieto Jerónimo Rengifo en 1568 y el establecido por doña María de Mendoza ${ }^{25}$ a favor de su hija doña María Manrique de Mendoza en las capitulaciones matrimoniales con su hijastro don Alonso de Granada Venegas Rengifo, a la que mejoró en el tercio y quinto (nn. 157, 207, 208). Hubo un quinto mayorazgo fundado, con el obligado permiso regio (n. 55), por don Pedro de Granada Venegas Manrique de Mendoza, en 1624, para su hijo Francisco de Granada Venegas Toledo, fallecido antes de tomar posesión ${ }^{26}$.

En reconocimiento a su calidad, persona y cargos desempeñados, Felipe IV tituló a don Pedro de Granada Venegas Manrique de Mendoza con el vizcondado de Miravalles en 1632 (nn. 45, 46), quien poco después representó al monarca sus servicios y los de sus antepasados solicitando la dignidad de marqués para su Casa, ruego que atendió el soberano con primera denominación de Campo Rey el

22. J.A. GARCÍA LUJÁN. "Don Alonso de Granada Venegas Rengifo, cuarto señor de la Casa de Granada (1540-1611)", en prensa.

23. J.A. GARCÍA LUJÁN. "De heráldica granadina. El linaje Granada Venegas, marqueses de Campotéjar", en F. MARSILLA. (coord.). Littera Scripta in honorem Prof. Lope Pascual Martinez, Murcia, 2002, vol. I-1, pp. 361-378.

24. J.A. GARCÍA LUJÁN. "Genealogía del linaje ..., pp. 29-33.

25. Casada en segundas nupcias con don Pedro de Granada Venegas Mendoza.

26. Otros mayorazgos ajenos a la Casa de Granada existentes en el Archivo eran el fundado por doña Inés de Barrientos en doña Mencía Carrillo (n. 586) y un traslado de los creados por los marqueses de Cañete y el conde de Tendilla (nn. 183, 184). 
marquesado y finalmente de Campotéjar, terminado de despachar, en pergamino, después de su muerte por la marquesa viuda (nn. 405, 361, 391, 53).

Señor de la taha de Marchena por herencia de su padre el Infante Ibn Selim, don Pedro de Granada fue desposeído de la misma por los Reyes Católicos en 1490, quienes la entregaron a don Gutierre de Cárdenas Chacón. Este expolio nunca fue olvidado por los Granada Venegas, que pleitearon con el duque de Maqueda y reclamaron su devolución a los monarcas siempre que tuvieron ocasión, y así hizo don Pedro de Granada Venegas Manrique de Mendoza al solicitar título de nobleza (n. 582).

El mayorazgo establecido por doña María de Mendoza $^{27}$, señora de Beamud y La Frontera, a favor de su hija doña María Manrique de Mendoza lo integraban la parte que le correspondía en Beamud, un censo de 10.500 ducados, varios miles de ducados, 2.000 fanegas de tierra en Cañavate, tierras en Cuenca, unas casas en esta ciudad, un censo de 4.000 ducados y tres sobre los molinos de La Aldehuela y otros bienes. Fallecida la mayorazga, su hijo don Pedro de Granada Venegas Manrique de Mendoza pleiteó con sus parientes Alarcón por la hacienda de Cuenca y Beamud (nn. 271, 272, 275, 289, 316), Buenache (nn. 314, 315), con don Juan Ruiz de Alarcón ${ }^{28}$ (nn. 583, 584, 210, 554), y sus correspondientes sentencias ejecutorias de los bienes del mayorazgo de doña María de Mendoza (n. 197), la tercera parte de Beamud con aceptación de doña Luisa de Cárdenas (n. 311), la posesión del estado de Barrientos por don Pedro Ruiz de Alarcón (n. 388), e inevitables gastos de abogados y escribanos (n. 318).

El pleito por el título de marqués de Campotéjar fue de carácter nominal, pues a la primera denominación de marqués de Campo Rey, gracia otorgada por Felipe IV a don Pedro de Granada Venegas Manrique de Mendoza, se opuso su hermanastro don Fernando de Granada Venegas Ochoa, inmediato sucesor en el mayorazgo y Casa, por no ser lugar de realengo y sí un cortijo dentro de la jurisdicción de la villa de Campotéjar adquirida, junto con la de Jayena, por don Pedro. Esta disparidad de criterios dio origen a diversas consultas de la Cámara de Castilla, memoriales y un larguísimo pleito (n. 175) ante el Consejo de Justicia que no acabó hasta 1642, al determinar que Campotéjar, y no Campo Rey, debía ser el lugar de mayorazgo que diese nombre al título de marqués, expedido el 1 de febrero de $1643^{29}$.

27. En su primer matrimonio con don Diego Ruiz de Alarcón, señor de Buenache de Alarcón y Villanueva del Río, procreó a don Juan Ruiz de Alarcón, sucesor en el mayorazgo paterno, a doña Inés de Barrientos casada con don Juan de Alarcón, doña Catalina que matrimonió con Juan Rodríguez, y a doña María Manrique de Mendoza que casó con don Alonso de Granada Venegas Rengifo.

28. Su testamento en (n. 315).

29. Su análisis con edición de los títulos de Vizconde de Miravalles y Marqués de Campotéjar en J.A. GARCÍA LUJÁN. "Don Pedro de Granada Venegas, I Marqués ...", vol. II, pp. 721-731. 
2. Mercedes, privilegios y dispensas. Nombramiento de caballeros de Órdenes Militares. Certificaciones personales. Memoriales de servicios. Pleitos personales. Correspondencia con la Casa Real. Correspondencia particular. Testamentos.

Entre otras y en reconocimiento de sus servicios durante y después de la Guerra de Granada, los Reyes Católicos concedieron a don Pedro de Granada y sucesores la merced de ir acompañados de una guardia personal de siete hombres armados (nn. 136, 89), confirmada por los monarcas posteriores (nn. 32, 36, 49, 125, 48), exención de alcabalas (n. 137), privilegio de franquicia (n. 153), inmunidad de las casas donde residieran en las que no podía entrar la justicia (nn. 138, 52), el alguacilazgo mayor de Granada ${ }^{30}$ a don Pedro (nn. 95, 140, 145), renunciado en su hijo don Alonso Venegas (n. 111), con el tiempo desvinculado de la Casa, e intentado su recuperación, sin éxito, por don Pedro de Granada Venegas Manrique de Mendoza, en 1610, (n. 378) con información favorable del Reino (n. 595) y jurídica de don Fernando Osorio (n. 154), y permiso para reedificar la fortaleza del castellón de Campotéjar (n. 109). Así mismo regidurías que los convirtieron en una dinastía de caballeros veinticuatro ${ }^{31}$ (nn. 140, 96, 65, 66, 4), perpetuada en don Pedro de Granada Venegas Manrique de Mendoza (n. 5) de modo oneroso (nn. 6-8) (2) $^{32}$ con licencia regia para renunciarla en vida o muerte (nn. 23,434$)^{33}$.

Al no tener el mayorazgo ningún lugar con jurisdicción sobre el que tomar título de Castilla, don Pedro de Granada Venegas Manrique de Mendoza compró en 1632 las jurisdicciones de Campotéjar, cuyas alcabalas había adquirido unos años antes $^{34}$, y Jayena ${ }^{35}$, lugares solariegos de la Casa cuya potestad quisieron poseer sin éxito su padre y abuelo, privilegios conservados en sendos libros encuadernados con cubiertas de badana con letras doradas en su exterior identificando el contenido (nn. 227-229, 234-235).

Y junto a estas mercedes y privilegios de la Casa de Granada, los personales: unos, donación de los Reyes Católicos de tierras y morales en Andarax a don Pedro de Granada (n. 139) y encargo a su secretario Hernando de Zafra para informarse sobre ciertos bienes reales nazaríes a fin de darlos a don Alonso Venegas y a doña Juana de Mendoza (n. 110); otros, al primer marqués de Campotéjar para andar en silla de manos o en carruaje ${ }^{36}$ (nn. 39, 22, 33), celebrar misa en la capilla

30. J.A. LÓPEZ NEVOT. "Los Granada Venegas, regidores, alguaciles mayores de Granada y procuradores de la ciudad en las Cortes de Castilla (siglos XV-XVI)", en J.A. GARCÍA LUJÁN. (ed.) Nobleza y Monarquía ..., pp. 339-342.

31. J.A. GARCÍA LUJÁN. "Genealogía del linaje ...", pp. 40-41; "Don Alonso de Granada ..." (en prensa). J.A. LÓPEZ NEVOT. “Los Granada Venegas ... ”, pp. 329-330, 336-337.

32. En tres pagos de 46.250 maravedíes.

33. Como bien libre que era determinó que los sucesores en la Casa y mayorazgo la pudieran comprar por 4.000 ducados.

34. Por 682.380 maravedíes, considerando su renta de 22.746 maravedíes al año, a 30.000 el millar. Despachado el privilegio el 12 de octubre de 1627.

35. J.A. GARCÍA LUJÁN. "Don Pedro de Granada Venegas, I Marqués ...”, p. 723.

36. Para sus desplazamientos, además de la silla de manos, disponía de una litera y dos coches. La litera de terciopelo carmesí con cortinas de damasco y alamares de oro con sillones. Uno de los carruajes era de baqueta ordinaria con cortinas de paño colorado y alamares de oro con sillones. El otro 
del Generalife (n. 1) y exención de huéspedes de aposento en su residencia madrileña durante setenta y dos años, a partir de 1622, con obligación de dar para el Aposento de Corte tres habitaciones de 13 pies de ancho por 17 de largo cada una con servicio de caballería, permutadas después de su muerte por 500 reales al año a ruego de la marquesa viuda (nn. 50, 51, 59, 408).

El ingreso en las Órdenes Militares fue ambición consumada por varios miembros del linaje, no siendo impedimento sus orígenes musulmanes y algún antecedente judío converso ${ }^{37}$. Sin requisito de dispensa, a la de Santiago pertenecieron todos los titulares de la Casa, salvo don Pedro de Granada Venegas Manrique de Mendoza que cruzó su pecho con la cruz de la más exigente de Alcántara, y su hermanastro don Fernando de Granada Venegas Ochoa por su estado eclesiástico de chantre de la Iglesia Catedral de Cuenca. Títulos, juntos a otros documentos anejos, originales o traslados, que se guardaban en el Archivo, como la cédula real para que don Pedro de Granada hiciera profesión de caballero en el convento de Uclés (n. 141), los de don Pedro de Granada Venegas Mendoza y su hermano don Egas (nn. 98, 99), don Alonso de Granada Venegas Rengifo (nn. 88, 91, 470), don Pedro de Granada Venegas Manrique de Mendoza (nn. 25, 26) y su hermano don Diego (n. 42). Aunque la falta de dispensa no significó que no fueran discutidos sus precedentes nazaríes y judeo conversos, y de ahí el auto del Consejo de Órdenes para que se dieran hábitos a los caballeros descendientes de la Casa de Granada (nn. 94, 473) y los papeles que se hubieron de llevar a Roma al efecto (n. 598).

Las certificaciones que aseguran la veracidad de un hecho también están presentes en el Archivo, circunscritas todas ellas a don Pedro de Granada Venegas Manrique de Mendoza, haciendo constar que fue capitán de la compañía del valle de Lecrín (nn. 35, 37), diputado a Cortes por el Reino de Granada en 1583 (n. 9), el sueldo que percibía por alcaide de la fortaleza de Salobreña (n. 10), que junto a la de Almuñécar sirvió más de treinta años (n. 44), el socorro que prestó a Adra (n. 40), las juras de gentilhombre de la boca de Felipe III (n. 19), de mayordomo de la reina Isabel de Borbón (nn. 38, 445), de lo que se le debía de los gajes de gentilhombre (n. 446) y de haber ocupado su asiento en el Consejo (n. 41). Servicios militares y cortesanos, junto con otros propios y de su Casa, que representó a Felipe IV en diversos memoriales (nn. 20, 60, 164, 376, 321, 86).

Extraña la escasa documentación relacionada en el Inventario sobre pleitos personales, limitada a la respuesta a la demanda que don Gil de Granada Rengifo puso a su primo y cuñado don Pedro de Granada Venegas Manrique de Mendoza (n. 455), las requisitorias de éste contra Onofre de Acevedo (n. 585), don Bernardino de Cárdenas (n. 588), José Montes 8n. 260), Antonio Pérez de Bustamante (n. 512), una de concierto entre sus hermanos don Diego y don Juan de Granada (n. 466), y otra de transacción con su madrastra doña María de Ochoa de Castro por la que se obligó a darle por la dote, arras y demás pretensiones 2.000 ducados a plazos y otros 200 al año (nn. 590, 593).

grande, verde, con cortinas de damasco y almohadones de terciopelo verde, con cortinas y estribos de invierno. Ambos fueron vendidos en la almoneda a don Pedro Francisco de Alarcón por 2.100 reales.

37. Su análisis en J.A. GARCÍA LUJÁN. "Genealogía del linaje ...”, pp. 38-39. 
Más abundante es la correspondencia mantenida por los monarcas con los señores de la Casa, siendo las más antiguas la discutida, por su probable falsedad, carta del infante don Alfonso, intitulándose rey de Castilla, al infante Ibn Selim Al-Nayyar agradeciéndole la fuerza militar que le había enviado (n. 146) (3) $^{38}$ las de los Reyes Católicos a Sidi Yahya al-Nayyar acerca de diversos asuntos (nn. 135, $150,151)$ y requiriéndole para que los jurase por reyes de Granada (n. 134) ${ }^{39}$.

Cartas reales de las que fue receptor don Alonso Venegas para que acuda ante la presencia regia (n. 115), sirva con el Gran Capitán en la Guerra de Italia (n. 120), vaya con el cardenal Cisneros a la conquista de Orán (n. 113), avisa la llegada del Turco a Motril (nn. 121, 130), agradece sus servicios (n. 124), en particular durante el levantamiento de las Comunidades de Castilla (n. 127), se recupere el Peñón de Vélez de la Gomera (n. 128), venida del Emperador a Granada (n. 129), y todo un legajo de traslados de las que envió a este segundo señor de la Casa (n. 383).

A su vez don Pedro de Granada Venegas Mendoza fue destinatario de otras misivas manifestando Carlos I su pesar por el fallecimiento de don Alonso Venegas (n. 97), encarece intervenga en el cabildo granadino para obtener los medios económicos con los que socorrer los proyectos imperiales (nn. 100, 101) y colabore militarmente en la cuarta guerra con Francia, pues como señor que recibía acostamiento de la Corona le requiere para que con su propia hueste forme parte del ejército imperial (nn. 102-104) ${ }^{40}$.

Cartas de llamamiento y apercibimiento para la guerra (n. 61) que en ocasiones se declina la participación, como así hizo Felipe II con don Alonso de Granada Venegas Rengifo en la anexión de Portugal por considerar mejor que permaneciera en Granada (n. 87) $)^{41}$, y en otras circunstancias las más placenteras y cortesanas de acompañar al monarca (nn. 54, 58), que no olvida agradecer a don Pedro de Granada Venegas Manrique de Mendoza su arrojo al llevar arcabuces y mosquetes con que socorrer Adra en 1620 de un asalto norteafricano (n. 47, 410).

Ingente es la correspondencia particular de diferentes personas y lugares, una verdadera red de correspondientes, recibida y enviada por don Pedro de Granada Venegas Manrique de Mendoza, archivada por años desde 1627 a 1642, coincidentes con el gobierno de Olivares y las rebeliones de Cataluña y Portugal, en una treintena de legajos (nn. 166, 219, 242, 266-269, 273, 284, 291, 292, 500-503, $508,509,515,532,534,541,559,562,564,566-568)$, y especial interés debe tener el legajo de cartas de don Fernando y don Juan de Granada Venegas Ochoa, futuros II y III marqués de Campotéjar de los que poco se sabe (n. 307).

38. Publicado por A. de BUSTOS Y BUSTOS, MARQUÉS DE CORVERA. Guerra y sitio de Baza en el siglo XV, Madrid, 1916, Apéndice I, edición facsímil Granada, 2008.

39. Editado por A. DE BUSTOS Y BUSTOS, MARQUÉS DE CORVERA. Breve estudio del tratado de don Fernando el Católico, rey de Castilla y Aragón, con Yahia Alnayar, antes príncipe Cidi Hiaya, en lo que se refiere a la Grandeza a favor del mismo reconocida, Madrid, 1916, Apéndice II, edición facsímil Granada 2008.

40. Editados en J.A. GARCÍA LUJÁN. Códice diplomático de la Casa de Campotéjar, Granada, 2009, docs. 7-12.

41. Ibidem, doc. 28 . 
Las declaraciones de última voluntad disponiendo de bienes y asuntos para después de la muerte del otorgante, no podían faltar en los asientos del Inventario, que recoge los testamentos de todos los señores del linaje y algunas consortes y hermanos: don Pedro de Granada (n. 144) ${ }^{42}$, don Alonso Venegas (n. 132) y esposa doña Juana de Mendoza (n. 112), don Pedro de Granada Venegas Mendoza (n. 105), don Alonso de Granada Venegas Rengifo ${ }^{43}$ (n. 93) y sus mujeres doña María Manrique de Mendoza (n. 366) y doña María Ochoa de Castro (n. 363), doña María de Velasco Benavides, primer cónyuge de don Pedro de Granada Venegas Manrique de Mendoza (n. 226), don Jerónimo de Granada (n. 326), don Diego de Granada Venegas Ruiz de Alarcón (n. 367) y fray Leandro de Granada, el más relevante de todos los segundones ${ }^{44}$. Monje benedictino en Salamanca en cuya Universidad fue maestro de Teología, definidor general de su Orden y primer traductor al español y divulgador de la visionaria Santa Gertrudis la Grande, fue autor de varias obras ascéticas y místicas. Entre los papeles que dejó a su muerte, ingresados en el Archivo, se hallan el concierto acordado con fray Torcuato Ortiz sobre su herencia paterna (n. 472), un legajo informando de su enfermedad y modo en que falleció (n. 365) y otros tres que contenían un innominado "libro del padre fray Leandro de Granada que se a de imprimir" (nn. 494, 495) y otro, manuscrito, intitulado Redención del mundo (n. 496), todo ello valioso para conocer su persona y obra literaria.

\section{Cargos y funciones de gobierno. Sidi Yahya al-Nayyar. Don Alonso Ve-} negas. Alcaidía del Generalife. Don Alonso de Granada Venegas Rengifo. Don Pedro de Granada Venegas Manrique de Mendoza.

Exiguos son los documentos inventariados sobre Yahya al-Nayyar, que se reducen a su nombramiento de virrey de Almería por "su primo el rey Abulacén" (n. 149) y el asiento y promesa que le hizo Fernando el Católico al entregar Baza (n. 147) faltando otros que a buen seguro estaban en el Archivo, pues a través de los vizcondes de Rías pasaron a la Casa de Corvera donde se hallaban a principios del siglo XX y fueron editados por su titular ${ }^{46}$.

Continuo de los reyes, don Alonso Venegas participó en la guerra con Francia por el Rosellón, proveyendo de pan a este (n. 108) y de cebada a Collioure (n. 107), jefe de una compañía de caballería e infantería para la defensa del partido de Motril (nn. 116, 117, 118, 122, 123, 126), con sumisión a su autoridad de los concejos de la costa del Reino de Granada (n. 114), fue nombrado capitán de la Armada (n. 119).

42. Publicado por A. de BUSTOS Y BUSTOS, MARQUÉS DE CORVERA. Guerra y sitio de Baza ..., Apéndice VI.

43. J.A. GARCÍA LUJÁN. "Testamentos de don Pedro y don Alonso de Granada Venegas", en M.C. CALERO PALACIOS et al. Homenaje a María Angustias Moreno Olmedo, Granada, 2006, pp. 613-623.

44. Sobre estos, J.A. GARCÍA LUJÁN. “Genealogía del linaje...”, pp.33-35.

45. Publicado por A. de BUSTOS Y BUSTOS, MARQUÉS DE CORVERA. Guerra y sitio de Baza..., Apéndice V.

46. Ibidem, Apéndices III y IV. 
La alcaidía del Generalife ${ }^{47}$, vinculada a la Casa de Granada en 1537 por las capitulaciones matrimoniales de doña María Rengifo Dávila con don Pedro de Granada Venegas Mendoza, fue ejercida por su hijo don Alonso (nn. 67, 349, 355) y nieto don Pedro de Granada Venegas Manrique de Mendoza (n. 27). Cargo vitalicio ampliado a dos vidas por merced regia (n. 3), después perpetuo (nn. 2, 173) y finalmente con jurisdicción civil y criminal (nn. 354, 356, 357, 359) valorando los servicios prestados y la segregación tiempo atrás de la Huerta del Ginarjo (n. 351) ${ }^{48}$. Real Sitio al que prestaron especial interés los monarcas (n. 352), litigada su Dehesa por la ciudad de Granada (n. 174), reparado en parte por sus alcaides (nn. 299, $245,358)$ y entregadas en arrendamiento sus huertas (n. 517). A destacar un plano con su diseño (n. 360).

La intervención de don Alonso de Granada Venegas Rengifo en la rebelión morisca de 1568-1570 ha sido recientemente analizada a partir de catorce documentos del Archivo del Marqués Corvera, copiados en un códice a finales del siglo $\mathrm{XIX}^{49}$, de los cuales hoy se conservan seis de los originales ${ }^{50}$, en tanto que los restantes han desaparecido ${ }^{51}$, y casi todos ellos referenciados en el Inventario de 1643 (nn. 69-86).

La milicia y la Corte, junto con la creación de un gran patrimonio, fueron los ejes vitales de don Pedro de Granada Venegas Manrique de Mendoza ${ }^{52}$. Militar, como alcaide de Salobreña en 1594 (nn. 14, 11, 12, 13, 15-17), de Almuñécar dos años después (nn. 29, 28, 56, 214, 533), tenencia ampliada, en 1617, por otra vida más, del hijo o hermano que designase, y perpetuada en propiedad, en 1640, por 1.000 ducados (nn. 30, 63, 64), e igualmente una regiduría de esta ciudad por juro de heredad comprada en 1.000 reales (n. 159). Cortesano, obligado por voluntad regia a aceptar el corregimiento de Ávila (n. 21), prorrogado en su ejercicio (nn. 31, 447) con expresión de gratitud de la ciudad castellana al Consejo de Cámara por su nombramiento (n. 34), y de vuelta en la Corte, en su calidad de mayordomo, miembro del Bureo y Casa de la Reina, junta de altos dignatarios palatinos presidida por el mayordomo mayor que resolvía los expedientes administrativos de la Casa Real y ejercía jurisdicción sobre las personas sujetas a su fuero, de cuya actividad son muestra una decena de legajos (nn. 435-442, 465, 469, 511), que como era habitual pasaron de la institución que los generaba al archivo personal de sus miembros, en este caso el de don Pedro de Granada.

47. J.A. GARCÍA LUJÁN. El Generalife, jardín del Paraiso, Granada, 2006.

48. Aunque por perpetuar por juro de heredad la tenencia y alcaidía del Generalife con sus huertas, dehesa y aprovechamientos pagó 2.000 ducados.

49. J.A. GARCÍA LUJÁN. Códice diplomático ..., pp. XXXVII-XLII, docs. 14-27.

50. Corresponden a los docs. 16, 20, 23, 24, 25 y 27 del Códice diplomático.... Se hallan en Archivo del Ministerio de Justicia, Título de Duque de Cidi Yahya, doc. 36 y 37 los docs. 16 y 27 del Códice, y los cuatro restantes en el AMCO, sin sign.

51. De los mismos existe en el precitado archivo nobiliario una regesta coetánea.

52. Sus hechos y exequias en C. ÁLVAREZ MÁRQUEZ, J.A. GARCÍA LUJÁN. "Las lecturas de don Pedro de Granada Venegas, I marqués de Campotéjar (1559-1643), Historia, Instituciones, Documentos, 35 (2008), pp. 149-158. 


\section{Patrimonio. Capitulaciones matrimoniales y dotes. Títulos de propie- dad y compraventa de bienes. Juros. Escrituras de obligación y deuda. Cen- sos. Pleitos por posesiones.}

Las capitulaciones matrimoniales y dotes concertadas por los titulares de la Casa de Granada están recogidas parcialmente en el Inventario, que cita las de Yahya al-Nayyar con Cettimeriem Venegas (n. 148), don Pedro del Granada Venegas Mendoza con doña María de Mendoza (nn. 545-547) ${ }^{53}$ y don Pedro de Granada Venegas Manrique de Mendoza con sus consortes doña María de Velasco Benavides (n. 542) y doña Leonor Rodríguez de Fonseca (n. 543); ésta aportó una dote de 85.895 reales de plata y oro (8.000 ducados), de ellos un censo de 12.000 reales sobre el Estado del duque de Alba (n. 233) ${ }^{54}$, y un juro de 3.000 ducados de principal sobre puertos secos de Portugal (n. 238) ${ }^{55}$.

Los títulos de propiedad y compraventa de bienes corresponden a las casas principales del mayorazgo instituido por don Alonso Venegas y don Pedro de Granada Venegas Mendoza (n. 340), un solar en la parroquia de la Iglesia Mayor de Granada frontero a las casas antiguas del linaje ${ }^{56}$ (n. 536), la alcaidía de Nerja (n. 471) y la casa en Madrid, junto a San Nicolás, donde residió don Pedro de Granada Venegas Manrique de Mendoza (nn. 236-237). Éste se hizo con un gran patrimonio agrícola al comprar tierras en el pago de Pizarrama en la Vega granadina (n. 230), el cortijo de San Pedro de la Canaleja, vendido - dice el Inventario- por Pedro Hidalgo, su mujer María de Mendoza y los hijos de Lázaro Porcel (n. 552), afirmación errónea pues lo adquirió en subasta a la Junta de Población de Granada, el de San Pedro de la Breña ${ }^{57}$ y los cuatro cortijos de Santa Polonia, llamados Santa Polonia, Fuente de don Pedro, Majadillas y Peñaflor, el derecho de construir una venta en Prado Redondo, término de Granada en el camino a Jayena, el cortijo de Corzola en esta villa (n. 265) y en Almuñecar la heredad de Cordobilla y una casa (nn. 158, 159, 232). Sin embargo, en el Inventario no se mencionan los títulos de compra de los cortijos de Miravalles, Campo Rey, Garnafate, El Juncar, La Solana, Los Noguerales y Haza Ajena, en tanto que los de las tierras en Salobreña y Almuñécar se hallarían en alguno de los legajos atinentes a estas ciudades. Otros títulos pertenecen a la escribanía de Alcaraz (nn. 364, 443), molinos de Peñaquebrada (n. 272) y compra de esclavos (338), de los cuales uno se llamaba Amete, de color membrillo cocho con una señal en la mejilla derecha con clavo; otro, del mismo color, atendía al nombre de Ramadán, moro berberisco, señalado en el labio superior, cristiano a la muerte del primer marqués de Campotéjar con el nombre de

53. Se hallaban en el Archivo las de su primer matrimonio con don Diego Ruiz de Alarcón, señor de Buenache (nn. 283, 587).

54. Escritura pública de 16 de septiembre de 1604, rentaba 700 reales y 22 maravedís al año.

55. De 34.824 maravedís de juro y renta anual.

56. Palacio de los Infantes. Una mitad del solar lo compró don Alonso de Granada Venegas Rengifo por 5.000 reales, y tomó a censo perpetuo, con facultad real, la otra, construyendo su hijo don Pedro de Granada Venegas Manrique de Mendoza tres tiendas, antes de su segundo matrimonio, llamadas "las tiendas nuevas".

57. Probable confusión con San Pedro de la Canaleja. 
Francisco del Espíritu Santo ${ }^{58}$; un tercero, por nombre Cardenillas, color mulato, pelo crespo con una mancha en el entrecejo, lo compró a su cuñada doña Catalina de Velasco Benavides en 250 ducados $^{59}$.

En las Cortes de Madrid en 1608, en las que se aprobó un servicio de diecisiete millones y medio, fue decisivo el voto de don Pedro de Granada Venegas Manrique de Mendoza, diputado por esta ciudad, al aceptar su parecer la mayor parte de los procuradores del Reino, por cuya actuación solicitó un título de nobleza y la devolución de la taha de Marchena ${ }^{60}$. Petición no atendida, pero a cambio recibió 100.000 maravedíes de juro (n. 24), que un cuarto de siglo después aún no estaban situados en los libros de Hacienda (nn. 167, 224), juro vitalicio al que hay que sumar otro en el servicio de millones de Granada (n. 421) y en las salinas de Espartinas (nn. 218, 514, 528, 529).

Escrituras de obligación y deuda numerosas, todas a favor del primer marqués de Campotéjar de diferentes personas y cantidades (nn. 176, 295, 317, 368, 384, 390, 393, 396, 397, 406, 427-430, 433, 458, 544, 597), de entre las que conviene individualizar las de don Mateo de Rojas y Pedro Fernández de Palma (nn. 399, 400), y todo un legajo de obligaciones de su primo y cuñado don Gil de Granada Venegas Rengifo (nn. 451, 452).

No menos abundantes censos perpetuos (nn. 336, 539) y temporales, deudores pocos $(169,180,301,448,449)$, acreedores los más, de diversos importes con los correspondientes pleitos por impago: don Jaime Pallas (nn. 288, 312), doña Luisa Carrillo (nn. 206, 518, 519), el conde de Aguilar (nn. 218, 209), 1.000 ducados de don Rodrigo de Herrera (n. 231), 4.000 ducados en Buenache (nn. 188, 310), 16.500 ducados en Cuenca (nn. 516, 528, 549) ${ }^{61}, 2.000$ ducados contra doña Luisa de Cárdenas, señora de Valdecabras (nn. 187, 505), 10.000 ducados sobre los propios y rentas de Toledo (nn. 189-191, 308, 309, 540), 6.000 ducados del conde de Colmenar de Oreja sobre los molinos de La Aldehuela ${ }^{62}(241,243,270,277,560$, $561)$ y 10.500 ducados de principal por el censo que gozaba el primer marqués de Campotéjar, como poseedor del mayorazgo fundado por su abuela materna doña María de Mendoza, y le pagaban don Francisco Centurión, marqués de Armuña (nn. 282, 521, 522, 589), e hija doña Leonor Centurión Mendoza, marquesa de Estepa (nn. 327, 550).

Sin faltar los pleitos por posesiones rústicas en Cuenca con sus parientes don Juan de Alarcón por la dehesa de Torralba (nn. 210, 474) y doña Luisa de Cárdenas por la tercera parte de Beamud (nn. 271, 275, 311). Pero el pleito que ocupó y amargó la vida a don Pedro de Granada Venegas Manrique de Mendoza fue el que

58. Comprados ambos al licenciado Alonso Álvarez de Llano en 1.600 reales, Madrid, 4 de octubre de 1632, tenían 35 y 36 años al fallecer su dueño.

59. Granada, 4 de septiembre de 1629, tenía 38 años cuando falleció don Pedro de Granada.

60. Solicitada su devolución por su padre y abuelo a monarcas anteriores, esta taha almeriense hubo de entregarla Sidi Yahya al-Nayyar a los Reyes Católicos a finales del siglo XV.

61. Corresponden a los censos de Buenache, doña Luisa de Cárdenas y el marqués de Armuña.

62. H. BALTANÁS. "Los molinos de la presa de la Aldehuela (Colmenar de Oreja): obras de remodelación de un complejo hidráulico en el río Tajo (siglos XVI-XVII”, en Actas del segundo congreso nacional de Historia de la Construcción, Coruña, 1998, pp. 35-39. 
litigó en la Chancillería granadina por la villa de Huétor del Marqués o de la Vega, hoy Huétor Santillán, que siendo de la Casa de Granada y mayorazgo llevaba más de setenta años sin poseerlo hasta que lo consiguió, con un gasto de 3.800 ducados más 3.500 en mejoras, aunque después de la vista y revista estaba pendiente de acabar en la Sala de Mil y Quinientas (nn. 161, 178, 185, 186, 192-195, 380- 382, 523). Éstas y otras causas judiciales estaban relacionadas en un extenso libro, encuadernado, con el rótulo "memoria de los pleitos" (n. 524).

5. Administración del Patrimonio. Inventarios de bienes. Libros de contabilidad. Correspondencia, cuentas y pleitos de administración. Cartas de pago. Liquidación de impuestos. Cuentas de obras privadas, gastos de casa, salarios y nóminas de empleados.

De los bienes y otras cosas pertenecientes a personas o depositados en custodia se redactaron los correspondientes inventarios, como fue el caso de los que dejó al morir doña María de Velasco Benavides, primera mujer de don Pedro de Granada Venegas Manrique de Mendoza (n. 223), los que estaban en la torre de la Casa de los Tiros, esto es, los cañones de artillería y mosquetes (n. 303), los recibidos por Francisco del Castillo (n. 222) y del menaje de casa y objetos que quedaron al cuidado de don Gil de Granada Rengifo cuando su primo don Pedro se trasladó, en 1619, a Madrid definitivamente (nn. 453, 456, 591). En un librillo de quince hojas, escrito de letra de Sebastián Romero, estaban inventariados todos los bienes del marqués de Campotéjar (n. 221). Igualmente, en memoriales estaban apuntados los bienes que dejó don Juan de Granada Venegas Ochoa en el castillo de Nerja (n. 212), los que quedaron en Granada cuando el futuro primer marqués de Campotéjar marchó a Madrid (n. 177), los gastos que hizo en los bienes del mayorazgo (n. 493), la renta que percibía (n. 563), sobre Jayena (n. 261) y la hacienda de la Casa de Granada (n. 330). Y asentado en libros de registro las haciendas de Granada y Campotéjar (n. 525, 578), de Granada en 1631 (n. 570) y todo el patrimonio en grandes volúmenes de a folio (nn. 569, 573).

Libros de contabilidad, pocos los inventariados para tan vasto patrimonio: de entradas y salidas de dineros (n. 577), de gasto, entradas y salidas de dinero en 1590 (n. 600), de cuenta de los años 1613 a 1628 (n. 574), de cargo y descargo de mayordomos en 1638 (n. 572), de cargo y descargo de Francisco del Castillo (n. 571), del cuarto del cortijo de Garnafate (n. 279) y del quinto de trigo, cebada y otras semillas de Jayena en 1641 (n. 245).

Un patrimonio señorial cuya administración exige una relación epistolar continua entre el señor y sus administradores, cartas misivas sistematizadas en legajos sobre la hacienda de Granada (n. 302), Granada y Jayena (n. 599), Campotéjar del año 1631 (n. 240), Jayena y Campotéjar de 1638 (n. 246), Jayena (nn. 248, 249, 251), Campotéjar (n. 255), de Francisco Arias del Castillo de 1637 (n. 264) y de Pablo del Castillo (nn. 510, 565).

Mayordomos y administradores de los bienes señoriales que dan cuenta puntual de su gestión económica, como así hicieron Cristóbal Acevedo (n. 404), el licenciado Aguilera (n. 213), Eugenio Álvarez (n. 320), don Francisco Arias del 
Castillo, mayordomo de Jayena en 1639 y gobernador de Campotéjar (nn. 220, 278), don Gregorio de Briones (n. 270), Vicencio Cañizares (n. 461), Pablo del Castillo (nn. 323, 491-493, 548), Pedro Díaz de la Torre (nn. 275, 459), don Juan de España (n. 460), Lope Fernández de Contreras, mayordomo en Granada (n. 297), Juan Luis de Figueroa, mayordomo en Jayena (n. 280), Andrés González, mayordomo en Campotéjar (n. 506), Diego Jiménez Flores, mayordomo en Jayena en 1636 (nn. 262, 263), Nicolás López, mayordomo en Huétor (nn. 171, 179, 181, 182), Antonio de Losada (nn. 256, 274), Alonso Martínez de Piqueras, mayordomo en Cañavate y Tarazona (Cuenca) en 1641 (nn. 215, 244, 270, 290), don Pedro Masquefa, mayordomo en Granada y Campotéjar en 1637 (nn. 250, 402), don Ramón Pallas (n. 272), Peñarroja (nn. 293, 298, 555), Melchor de Rivas y Blas de Martos (n. 281), el licenciado Rivera (n. 527), Francisco de Rivera, mayordomo en Jayena, (n. 285), Jacinto de Rivera, mayordomo en Granada y Campotéjar (nn. 296, 304), Sebastián Romero (nn. 276, 287, 553), Fernando Suárez (n. 386), Juan de Suescun, mayordomo, (nn. 247, 252), don Fernando Venegas, mayordomo en Campotéjar, ¿el hijo natural de don Alonso de Granada Venegas Rengifo y hermano de padre del primer marqués de Campotéjar? (n. 507) y Alonso de Villalúa (n. 527) ${ }^{63}$. Dos de ellos terminaron deudores en las cuentas de su mayordomía con los consiguientes pleitos en su contra sobre la administración que habían llevado a cabo: Francisco de Rivera (n. 286) y Pablo del Castillo (nn. 225, 346-348, 499).

Sin faltar cartas deudoras del primer marqués de Campotéjar en remate de cuenta con Juan de Criales, mercader (n. 417) y Lázaro Midense, genovés ${ }^{64}$ (n. 431), y de pago de diversos años (nn. 160, 328, 329, 333, 387), diferentes individuos (nn. 319, 344, 413, 414, 450, 457, 596), personas concretas tales como Catalina de Vario (n. 168), doña Mariana de Granada Venegas Rengifo (n. 313), doña Antonia de Solórzano (n. 344), el licenciado Morales Ballesteros (n. 389), Blas Muñoz de Ramos (n. 401), don Juan de Granada Venegas Ochoa (n. 412), Andrés Chico (n. 424), don Juan Porcel, soldado montado (n. 426), don Francisco Guillamas (n. 464), Catalina de Canseco (n. 475), Manuel de Vega, escribano del número de Santander (n. 558), e Iglesia de Granada (n. 306), abogados, relatores y procuradores (n. 344).

Como noble titulado don Pedro de Granada Venegas Manrique de Mendoza estaba obligado a concurrir personalmente a los ejércitos con un determinado número de soldados mantenidos a su costa, deber del que quedó exento a cambio de pagar 3.600 reales al año, servicio de lanzas, para sostener los presidios ${ }^{65}$ (nn. 165, $416,419,423,520)$.

63. Es posible que también fuera administrador Francisco López Cavallón (n. 239).

64. Residente en Madrid en 1628, agente de lanas de Bartolomé Spinola, Octavio María Cavana y otros hombres de negocios genoveses, C. ÁLVAREZ NOGAL. "El Factor General del Rey y las finanzas de la Monarquía Hispánica”, Revista de Historia Económica, XVII (otoño-invierno 1999), p. 519.

65. J.I. FORTEA PÉREZ. "De nobles, lanzas y presidios", en R. FRANCH BENAVENT, R. BENITEZ SÁNCHEZ-BLANCO. (eds.) Estudios de historia moderna en homenaje a la profesora Emilia Salvador Esteban, Valencia, 2008, vol. I, pp. 189-212. 
Al trasladarse a Madrid compró un solar al licenciado Bernardo Matienzo y otras personas en 1622, donde edificó varias casas principales y accesorias en la calle del Factor, parroquia de San Nicolás, colindando con la casa del duque de Pastrana sobre cuyo jardín tenía derecho de agua vertiente (n. 557); fue maestro de obras Juan Lázaro (nn. 371-373), la carpintería corrió a cargo de varios ebanistas (n. 374, 379) y se trazó una escalera nueva (n. 538). Residencia en la que era servido por criados, cuyos nombres eran inscritos en libros de asientos (nn. 575, 576), así como cartas de pago de los salarios cobrados (nn. 342, 409), cuentas menudas con sirvientes (n. 468) o revocación de emolumentos a profesionales (nn. 392, 415). Y con la misma precisión eran anotados en libros de cuentas los gastos de casa (n. 211), de su recámara personal (n. 498) o se archivaban los pagos abonados a los panaderos Andrés Chico (n. 403) y Diego del Valle (n. 535) o a los plateros Juan Calvo (n. 170) y Juan de Frías por una cantimplora grande con su cubo, de plata, que a buen seguro llevaría el primer marqués de Campotéjar en sus viajes y jornadas de caza (n. 463).

Finamente, tres son los registros del Inventario sobre obras pías: una capellanía en Nerja (n. 259), otra instituida por doña Catalina de Benavides (n. 362) y el patronato que fundó doña Francisca de Mendoza mediante acuerdo con el futuro santo fray Juan de la Cruz (nn. 162, 216, 217) para erigir el Convento de Carmelitas Descalzos de los Santos Mártires.

\section{INVENTARIO DEL ARCHIVO}

1643, marzo 3- 5. Madrid.

Inventario del Archivo de la Casa de Granada, realizado a la muerte de don Pedro de Granada Venegas Manrique de Mendoza, titular de la misma y I marqués de Campotéjar.

Archivo Histórico de Protocolos Notariales de Madrid, Leg. 2813, ff. 31r-52v.

// ${ }^{\beta 1 r}$ (Al margen): Prosigue el inventario.

En la villa de Madrid, a tres días del dicho mes y año de março de seiscientos y quarenta y tres años, ante mí el dicho escrivano, la parte de los dichos testamentarios del marqués de Campotéjar se prosiguió el inventario de vienes del dicho marqués en la forma y manera siguiente.

Abriose un escritorio donde están los papeles del señor marqués, que es de pino y tiene siete cajones y en ellos se allaron los papeles siguientes.

Primeramente, un libro con cubierta de becerro que tiene una cédula encima en que dice “don Pedro de Granada, quinto de la Cassa, primero marqués de Campotéjar", y en él están los papeles siguientes:

1. Un buleto del nuncio de su santidad para poder decir misa en la capilla real de Jeneralife.

2. Una cédula real de perpetuidad de la alcaidía de Jeneralife, fecha en favor del dicho señor marqués en Madrid a veinte y tres de enero de seiscientos y treinta años.

3. Otra cédula orijinal en que su magestad hace merced al dicho señor marqués que si muriese antes que mi señora la marquesa, goce su señoría la alcaidía de Jeneralife por su vida, fecha en Aranjuez a veinte y dos de abril de seiscientos y veinte y dos años. 
4. Título orijinal de la veinte y quatría de Granada en caveça del dicho señor marqués.

5. Perpetuación de la dicha veinte y quatría.

6. Carta de pago de quarenta y seis mill ducientos y çinquenta maravedís pagados a Carlos Trata por la paga de la perpetuación de la dicha veinte y quatría.

7. Otra carta de pago de la misma cantidad pagada a Vicencio Escarçafijo por la misma raçón.

8. Otra carta de pago de la misma cantidad pagada por la dicha raçón a Joseph de la Torre, cesonario de doña Ysavel Vivanco, que todas //31v están devajo de una cubierta que dice "perpetuación de la veinte y quatría de Granada".

9. Certificación de Antolín de la Serna de como el señor marqués fue diputado del Reino por el de Granada el año de quinientos y ochenta y tres.

10. Certificación del sueldo que tiene la fortaleça de Salobreña.

11. El pleito omenaje que el dicho señor marqués hiço de la dicha fortaleça de Salobreña.

12. Carta del rey Phelipe 2 al dicho señor marqués sobre cosas tocantes a la dicha fortaleça.

13. Cédula del rey don Phelipe 2 para que se le pague al dicho señor marqués el dicho sueldo enteramente.

14. Título del rey don Phelipe Segundo al dicho señor marqués de la dicha alcaidía de Salobreña.

15. Cédula para que se le paguen al dicho señor marqués veinte fanegas de trigo cada mes a quenta de su sueldo.

16. Cédula del rey don Phelipe 2 para que el dicho señor marqués pueda tener teniente en la dicha alcaidía.

17. El entrego que se hiço del artillería y demás pertrechos de la dicha fortaleça a Juan Martín de Tarifa.

18. Carta del duque de Lerma scrita al dicho señor marqués para que dispusiese los ánimos del cavildo sobre cierto servicio.

19. Certificación de cómo el dicho señor marqués juró de jentilhombre de la boca de su magestad.

20. Memorial de los servicios del dicho señor marqués.

21. Título de correjidor de la ciudad de Ávila.

22. //32r Cédula para que el dicho señor marqués pueda andar en coche.

23. Cédula del rey don Phelipe 3 para que el dicho señor marqués pueda renunciar en vida o en muerte la veinte y quatría de Granada.

24. Carta de don Juan de Acuña de la merced que hiço su magestad al dicho señor marqués de cien mill maravedís de juro de por vida.

25. Título del ávito de Alcántara del dicho señor marqués.

26. Otras cédulas para que pueda recibir el dicho ávito y hacer profesión en Madrid.

27. Título original del alcaidía de Jeneralife.

28. Cédula de su magestad y aprovación de teniente de la fortaleça de Almuñécar.

29. Título del alcaidía de la dicha fortaleça al dicho señor marqués.

30. Prorrogación por otra vida de la dicha fortaleça.

31. Prorrogación del correjimiento de la ciudad de Ávila.

32. La información y sobrecédula real de la facultad de las siete cédulas para armas del previlejio de la Casa.

33. Cédula de su magestad para que el dicho señor marqués pueda andar en coche.

34. Carta que escrive la ciudad de Ávila dando gracias al Consejo de Cámara por aver echo correjidor al dicho señor marqués. 
35. Certificación de que la ciudad de Granada nombra por capitán de la jente del valle de Lecrín al dicho señor marqués.

36. Traslado autoriçado para dar cédulas de armas.

37. Cédula de su magestad de la compañía del valle [de Lecrín].

38. //32v Certificación de Eujenio de Marbán de como juró el dicho señor marqués por mayordomo de la reina nuestra señora.

39. Cédula del rey don Phelipe 4 para andar en silla de manos el dicho señor marqués.

40. Certificación del marqués de Maença del socorro de Adra.

41. Certificación de que el señor marqués se a sentado en los estrados del Consejo.

42. Certificación de don Gregorio de Tapia del ávito del señor don Diego de Granada.

43. Testimonio del auto del Consejo de Inquisición sobre la calidad del dicho señor marqués y los de su Casa.

44. Certificación de don Íñigo Briceño de como el dicho señor marqués a servido las alcaidías de Salobreña y Almuñécar más de treinta años.

45. Título de vizconde de Miravalles al dicho señor marqués y un traslado del dicho título autoriçado.

46. Testimonio de las preheminencias que goça el que tiene título de vizconde.

47. Carta del rey don Phelipe 3 al dicho señor marqués agradeciendo el socorro de Adra.

48. Última cédula de armas dada al dicho señor marqués.

49. Confirmación de las cédulas para dar armas.

50. Cédula de esención de guésped de aposento de las cassas principales del dicho señor marqués por treinta y dos años.

51. Un traslado simple de la dicha cédula.

52. Confirmación de la cédula de inmunidad de la cassa del dicho señor marqués.

53. Traslado simple del título de marqués de Campotéjar.

54. Una carta del secretario Bernardo Gonçález apercibiendo al señor marqués para salir con su magestad.

55. Facultad dada al dicho señor marqués para hacer mayorazgo de sus bienes libres.

56. Decreto de la ciudad de Almuñécar cerca del socorro que hizo el dicho señor marqués a aquella ciudad.

57. Traslado simple de la cédula de la inmunidad de la casa.

58. //33r Carta de su magestad previniendo al dicho señor marqués para la jornada de Burgos.

59. Cédula orijinal de esención de las casas principales por otros quarenta años más.

60. Memorial impreso de los servicios del dicho señor marqués.

61. Cartas de su magestad de llamamiento y apercibimiento para las jornadas de guerra.

62. Traslado sacado de los archivos de Simancas para que se guarden las casas del dicho señor marqués.

63. Traslado de la cédula orijinal del título de la perpetuación del alcaidía de la ciudad de Almuñécar.

64. Carta de pago y finiquito que otorgó Christóval de Aguilera de los mill ducados de la perpetuación del alcaidía de la dicha ciudad de Almuñécar.

Todos los quales dichos papeles por la orden que ban referidos están en el dicho libro, unos sueltos y otros cosidos en él, y se cerró y bolvieron a meter dentro.

Más otro libro con cubierta de becerro que tiene una cédula pegada que dice "don Alonso de Granada Venegas, 4 de la Cassa", y dentro de él están los papeles siguientes:

65. Una carta de la ciudad de Granada en recomendación del dicho señor don Alonso a su magestad quando murió el señor don Pedro, su padre. 
66. Título de la veinte y quatría de Granada al dicho señor don Alonso.

67. Título del alcaidía de Jeneralife al dicho señor don Alonso.

68. Carta de la ciudad de Granada al dicho señor don Alonso para que no usse de la facultad de guardar la caza.

69. Carta de los naturales del reino de Granada al rey don Phelipe Segundo de fidelidad por medio del dicho señor don Alonso.

70. Carta del rey don Phelipe Segundo al dicho señor don Alonso pidiéndole parecer en la población del reino de Granada.

71. //33v Carta del rey don Phelipe Segundo al señor don Juan de Austria en que le encomienda al señor don Alonso.

72. Carta del rey don Phelipe 2 al marqués de Mondéjar en recomendación del dicho señor don Alonso.

73. Carta de su magestad al dicho señor don Alonso agradeciéndole los servicios que hiço en el reino de Granada.

74. Patente de capitán de caballos al dicho señor don Alonso del señor don Juan de Austria.

75. Carta de su magestad al dicho señor don Alonso agradeciéndole el deseo que tiene de que se acave el levantamiento de Granada.

76. Carta del señor don Juan de Austria enviando a llamar al dicho señor don Alonso para cosas de mucha importancia.

77. Orden del señor don Juan de Austria dada al señor don Alonso con las condiciones que se admitirán los levantados del aquel reino.

78. Orden del señor don Juan de Austria para que se pague cada mes la compañía de jinetes del dicho señor don Alonso.

79. Patente del señor don Juan de Austria al dicho señor don Alonso para el rendimiento de los moriscos revelados.

80. Instrución del señor don Juan de Austria al dicho señor don Alonso para la redución de los dichos moriscos.

81. Declaración y orden consultada con el señor don Juan de Austria de los salarios que an de llevar los que andan con el dicho señor don Alonso.

82. Orden del señor don Juan de Austria para que se cumplan las libranças que diere el dicho señor don Alonso.

83. Orden del comendador mayor de Castilla dada al señor don Alonso cerca de la redución de los revelados.

84. //34r Facultad del comendador mayor de Castilla al señor don Alonso para levantar las cuadrillas.

85. Billetes del comendador don Luis de Quesada al dicho señor don Alonso.

86. Memorial de los servicios del dicho señor don Alonso.

87. Carta del rey don Phelipe 2 al dicho señor don Alonso en respuesta de averse ofrecido para la jornada de Portugal.

88. Traslado del título del ávito del dicho señor don Alonso.

89. Traslado de la facultad que dieron los señores Reyes Católicos al señor don Pedro de Granada primero para las siete cédulas de armas.

90. Raçón del linaje de Granada.

91. Papeles tocantes al ávito del señor don Alonso de Granada.

92. Memoria de las informaciones que se presentaron para verificar la limpieça de Diego de Francos.

93. Testamento del dicho señor don Alonso. 
94. Auto del Consejo de Órdenes para que se den ávitos a los cavalleros descendientes de la Casa de Granada.

Todos los quales papeles se volvieron a guardar dentro del dicho libro y se volvió a cerrar.

Más otro libro como los pasados que tiene otra cédula pegada que dice "don Pedro de Granada tercero de la Casa", y dentro se allaron los papeles siguientes:

95. Título de alguacil mayor de Granada al dicho señor don Pedro.

96. Título de la veinte y quatría de Granada al dicho señor don Pedro.

97. $/{ }^{34 v}$ Carta del emperador don Carlos al dicho señor don Pedro en ocasión de la muerte de don Alonso, su padre.

98. Título orijinal del ávito de Santiago del dicho señor don Pedro y un traslado de él autorizado.

99. Traslado con provisión de los títulos de ávito de don Pedro de Granada y don Egas de Mendoza, su hermano.

100. Carta del emperador al dicho señor don Pedro para que dispusiese en el cavildo de Granada cierto servicio.

101. Otra carta del dicho señor emperador en la misma conformidad.

102. Carta del dicho señor emperador avisando al dicho señor don Pedro de los disinios del rey de Francia por Navarra y Perpiñán.

103. Carta del emperador al dicho señor don Pedro agradeciéndole averse puesto a punto de guerra para irle a servir.

104. Carta del emperador al dicho señor don Pedro dándole quenta de los disinios del rey de Francia.

105. Testamento del dicho señor don Pedro.

Todos los quales papeles se allaron dentro del dicho libro y se volvieron a meter en él y se cerró.

Más se inventarió otro libro como los demás y en la cubierta está pegada una cédula que dice "de don Alonso de Granada segundo de la Cassa", y en él se allaron los papeles siguientes:

106. Título de la vitoria de la Vega y de las siete vanderas que ganó en ella.

107. //35r Cédula de los Reyes Cathólicos para que se le paguen ochocientas y seis mill maravedís al dicho señor don Alonso para provisión de las fronteras para que provea de cevada a Colibre.

108. Cédula de los dichos señores Reyes Católicos al dicho señor don Alonso para que provea de pan a Rosellón.

109. Cédula de los Reyes Católicos para rehedificar la fortaleça del castellón de Campotéjar.

110. Carta de los señores Reyes Católicos a Hernando de Zafra para averiguar ciertos bienes reales y darlos al dicho señor don Alonso y a doña Juana de Mendoza, su muger.

111. Título de alguacil mayor de Granada al dicho señor don Alonso.

112. Testamento de la señora doña Juana de Mendoça, muger del dicho señor don Alonso.

113. Carta del rey Católico al señor don Alonso para que vaya con el cardenal fray Francisco Ximénez para que vaya a la guerra de África, quando se tomó a Orán.

114. Cédula del rey Católico en que manda a los concejos de la costa del reino de Granada obedezcan al dicho señor don Alonso.

115. Carta del señor rey Católico en que le manda llamar al dicho señor don Alonso.

116. Cédula del rey Católico para que pueda hacer jente en el reino de Granada. 
117. Cédula del señor rey Católico para que ningún pescador pueda salir de noche hasta que ayan salido los atajadores.

118. Cédula del rey Católico para que los salteadores que prendiere la jente del dicho señor don Alonso se le [dé] por cada uno ocho mill maravedís.

119. Provisión de la señora reina doña Juana $/ /{ }^{35 v}$ y don Carlos, su hijo, en que hacen capitán del armada al dicho señor don Alonso.

120. Carta del dicho señor rey Católico en que le encarga al dicho señor don Alonso baya a servir con el Gran Capitán a la guerra de Italia.

121. Carta del señor rey Católico avisando al señor don Alonso que los enemigos vienen sobre Motril.

122. Cédula del señor rey Católico al señor don Alonso, su capitán, para que dé quince peones a otra compañía.

123. Minuta de los jinetes y peones de las compañías del dicho señor don Alonso.

124. Carta del señor rey Católico al dicho señor don Alonso en agradecimiento de lo bien que le sirve y que se comunique con el marqués don Íñigo de Mendoça.

125. Traslado y confirmación de las siete cédulas de armas.

126. Memorial que dio el señor don Alonso de la forma que se avía de tener en la guarda de la jente del reino de Granada.

127. Carta del emperador don Carlos al señor don Alonso en agradecimiento de los muchos servicios que le a echo en la ocasión de las Comunidades.

128. Carta del emperador al dicho señor don Alonso en la ocasión de la jornada del Peñón.

129. Carta del emperador desde Sevilla avisando de su venida y de la señora emperatriz.

130. Carta de la señora emperatriz al dicho señor don Alonso avisándole de la bajada del turco.

131. Cédula del emperador para la consultoría de la Inquisición del padre Phelipe de Mendoça.

132. Testamento del dicho señor don Alonso.

133. Testimonio del auto que proveyeron los señores //36r del Consejo de Inquisición cerca de dicha consultoría.

Todos los quales dichos papeles se allaron en el dicho libro y se volvieron a meter en él.

Más se inventarió otro libro como los demás y en la cubierta está una cédula que dice "don Pedro de Granada el primero", dentro del qual ay los papeles siguientes:

134. Una carta de los señores Reyes Católicos para que el dicho señor don Pedro lo jurase por rey de Granada (sic).

135. Otra carta de los dichos señores Reyes en respuesta de avelle enviado a visitar.

136. Cédula de los señores Reyes Católicos para poder dar siete cédulas de armas.

137. Previlejio de alcabala dado al dicho señor don Pedro.

138. Cédula de inmunidad de las cassas donde viviere el dicho señor don Pedro y los descendientes de su Cassa.

139. Merced de los señores Reyes Católicos al dicho señor don Pedro de tierra y morales en Andarax.

140. Título de rejidor y alguacil mayor de Granada al dicho señor don Pedro.

141. Cédula de los señores Reyes Católicos para que el dicho señor don Pedro vaya a hacer profesión al convento de Uclés.

142. El título de las cinco granadas.

143. Un poder dado por el dicho don Pedro al bachiller Garci López de Chinchón.

144. Testamento original del dicho señor don Pedro. 
Más otro libro en la conformidad que los demás y con las mismas cubiertas con una cédula pegada que dice "don Pedro de Granada el primero de antes de su santa conversión", y en él ay algunas cartas y papeles tocantes al dicho señor don Pedro de los señores Reyes, que son como siguen:

145. Traslado de una cédula del oficio de alguacil mayor //36v de la ciudad de Granada.

146. Carta del infante don Alonso intitulándose rey de Castilla escrita al infante Celín agradeciéndole la infantería y cavallería que le avía enviado.

147. El asiento orijinal que el señor rey Católico hiço con Cidi Aya, hijo del infante de Almería, quando le entregó a Baza.

148. Tradución de la carta dotal del casamiento con la señora de la Cassa de Granada.

149. Traslado del título de virrey que tuvo Cidi Aya de su primo el rey Abulacen de Granada.

150. Carta del señor rey Católico a Cidi Aya Anayar de creencia.

151. Carta de los señores Reyes Católicos a Cidi Aya en que dice oyó a su hijo todo lo que le dijo de su parte.

Todos los quales dichos papeles se volvieron a meter en el dicho libro y se cerró.

152. Más se inventarió otro libro de tablas con un sello de plomo en que están las entregas que se hicieron por los reyes moros (sic) de la ciudad de Granada.

153. Previlejio de las franqueças que concedieron los señores Reyes Católicos a los sucesores de la Cassa de Granada.

154. Unos papeles tocantes al oficio de alguacil mayor de Granada en que está una información en derecho que empeçó a escrivir don Fernando Osorio.

155-157. Otro libro de pergamino en que están el mayorazgo que fundó el señor don Alonso 2, y el que fundó el comendador Xil Vázquez Rengifo, y el que fundó la señora doña María de Mendoça en doña María Manrique, su hija.

En el segundo cajón del dicho scritorio se hallaron los papeles siguientes:

158. Un libro de folio con pergamino con buelta que dice "título de los cortijos de Santa Polonia".

159. $/ /{ }^{37 r}$ Otro legajo de papeles doblados en quarto con un pergamino por cubierta que en él dice "títulos de Santa Polonia, Cordovilla y San Pedro de la Breña y fuente de Restával y de las ventas camino de Jaiena y Prado Redondo, casa de Almuñecar y rejimiento perpetuo".

160-161. Otro legajo de papeles doblados, en forma de memorial, atados con una cuerda, de cartas de pago del año de seiscientos y treinta y uno, y otro del pleito de Güetor.

162. Otro legajo de papeles doblados en quarto en que están las scripturas tocantes al patronazgo que fundó la señora doña Francisca de Mendoça.

163. Otro legajo de papeles, de folio, que dice "linaje de $<\operatorname{los}$ reyes $>$ de Granada".

164. Otro legajo de papeles, de quarto, en que están memoriales del dicho señor marqués y sus servicios, y en la cubierta dice "linaje de Granada en Portugal".

165. Otro legajo de papeles doblados, en quarto, tocantes a las lanças de presidios.

166. Otro legajo de papeles de cartas misivas del año de seiscientos y treinta y nueve.

167. Otro legajo de papeles doblados, en forma de memorial, en que están libranzas de lo que se deve al señor marqués del juro de los cien mill maravedís de renta.

168. Una carta de pago de Catalina de Vario.

169. Quenta que envió Juan de Ayala, vezino de Cuenca, del censo que se paga a la yglesia .

170. Quenta con Juan Calvo, platero.

171. Otro legajo doblado, en forma de memoriales, tocante a Nicolás López, mayordomo de la hacienda de Güétor del dicho señor marqués. 
172. Otro legajo doblado, en la misma forma, que dice "papeles tocantes a la hacienda de Madrid y a los quinientos maravedís de censo que estavan sobre la güerta que trocó don Pedro de Porras".

Todos los quales dichos papeles se volvieron a meter en el dicho cajón.

$/ / 37 v$ En el tercero cajón estavan los papeles siguientes:

173. Un libro de folio con su pergamino que dice "Jeneralife y los títulos del alcaidía y perpetuación y otros papeles tocantes de ella".

174. Otro libro de folio con pergamino buelto en que está la carta executoria de la dehessa y términos de Jeneralife, litigada con Granada.

175. Otro legajo de papeles de a folio, entremetidos otros de a quarto, y en forma de memorial, atado con ilo de cartas, que dice la cubierta "papeles tocantes al pleito con el señor don Fernando, chantre de Cuenca".

176. Otro legajo de papeles atados, en forma de memorial, tocantes a don Luis de Villagutierre de algunas deudas que debe al dicho señor marqués.

177. Otro legajo de papeles, en forma de memorial, atado, que en la cubierta dice "raçón del hacienda mía que quedó en Granada a principio de diziembre de seiscientos y diez y nueve".

$\mathrm{Y}$ en el quarto cajón se inventariaron los papeles siguientes:

178. Un legajo de informaciones sobre el pleito de Güétor.

179. Otro legajo de papeles de la quenta de Nicolás López.

180. Otro legajo atado, en quarto, de la scritura de censo que se otorgó sin poder por Francisco de Castillo.

181. Otro legajo atado, en quarto, de la quenta y raçón de la renta de trigo y cevada de Güétor.

182. Otro legajo de papeles atado tocante a Güétor y al dicho Nicolás López.

183-184. //38r Otro legajo, en quarto, en que están traslado de los mayorazgos de los marqueses de Cañete y conde de Tendilla.

Los quales papeles se volvieron a meter en el dicho cajón.

Y en el quinto cajón se hallaron los papeles siguientes:

185. Un legajo de informaciones en derecho sobre el pleito de Güétor, atado, en folio.

186. Otro memorial del pleito de Güétor enquadernado en pergamino.

187. Una scriptura de censo de dos mill ducados de principal, fecha en Cuenca ante Diego de Medina, escrivano público.

188. Otra scritura de censo de quatro mill ducados de principal por la dicha raçón.

189. Testimonio de Antonio Gómez, receptor del pleito sobre el cumplimiento del remate de los diez mill ducados del censo de Toledo.

190. Otro libro enquadernado en pergamino de los títulos que tiene el dicho señor marqués en virtud de que le pertenece el dicho censo de los diez mill ducados.

191. Otro libro como el pasado por donde pertenecen a doña María de Andrada.

192. Otro libro encuadernado, con cintas, que es la executoria que se ganó en Granada en el pleito de Güétor.

193. Otro legajo, en folio, de informaciones en derecho de Güétor.

194. Otro legajo de memoriales e informaciones sobre el dicho pleito.

Todos los quales dichos [papeles] se bolvieron a meter en el dicho cajón.

Y en la sesta gaveta se allaron los papeles siguientes:

195. Un legajo de papeles, de folio, que son memoriales del pleito de Güétor.

196. //38v Otro legajo, de folio, que dice "breve relación del pleito de Güétor".

197. Un libro enquadernado, con cintas, que es la executoria de los bienes del mayorazgo de mi señora doña María de Mendoza, mi abuela. 
198-205. Otro legajo de papeles, atado, en folio, tocante a los Renjifos de Ávila, en que ay dos libros de pergamino buelto que dicen "filiación del muy ilustre señor don Pedro de Granada, y otro sin pergamino que dice lo mismo, y un traslado del mayorazgo que instituyó últimamente el señor don Alonso de Granada Venegas, segundo de la Cassa; y otro traslado del testamento de Vicente Renjifo, y otro quaderno que dice "sucesión de Xil González de Ávila", y otro traslado del testamento y cobdicilo de Jil Vázquez Rengifo de Avila, y un quaderno de la Guerra de Granada.

206. Otro quaderno del processo de execución a pedimiento del dicho señor marqués contra doña Luisa Carrillo por setecientas y doce mill y cincuenta y nueve maravedís.

207. Mayorazgo orijinal que fundó la señora doña María de Mendoça en favor de la señora doña María Manrique.

208. Otro de mejora de tercio y quinto de la dicha señora doña María Manrique.

209. Un legajo del pleito del dicho marqués contra los bienes de la condesa de Aguilar.

210. Otro legajo del remate que se hiço en el pleito de don Juan de Alarcón.

Los quales dichos papeles se volvieron a meter en el dicho cajón.

211. Y en el último cajoncillo se alló un libro, a lo largo, de quentas que tenía el dicho señor marqués del gasto de cassa hasta el año de seiscientos y treinta y quatro.

212. //39r Otro legajillo de papeles en forma de memoriales que dice uno "memoria de los vienes que dejó don Juan de Granada en el castillo de Nerja".

213. Otro legajo que es la quenta con el licenciado Aguilera.

Todos los quales dichos papeles se metieron en el dicho scritorio y se volvió a cerrar y en este estado se quedó el dicho inventario para proseguir en él adelante. Son testigos don Matheo de Roxas y Sebastián Romero y otros criados de cassa. Doy fe, ante mí, Antonio de Carvajal (rubricado).

(Al margen): Proseguimos inventario.

En la villa de Madrid, a quatro de março del dicho año, ante mí el dicho escrivano por parte de dichos testamentarios se prosiguió el dicho inventario en la forma siguiente.

Abriose otro scritorio con siete cajones y en el uno de ellos se allaron los papeles siguientes:

214. Un legajo de papeles atados, en quarto, que dice "legajo de papeles tocantes a Almuñécar".

215. Otro legajo de papeles atado, en quarto, con una cubierta de papel que dice "cartas de pago y testimonios de la quenta que dio Alonso Martínez de Piqueras el año de mill y seiscientos y treinta y cinco".

216. Otro legajo de papeles atado, en quarto, en que está un traslado de la scriptura de transación entre el padre fray Juan de la Cruz y otros interesados sobre la fundación de la señora doña Francisca de Mendoça.

217. Otro traslado del testamento de la dicha señora doña Francisca y otros papeles tocantes a ello.

218. Otro legajo de papeles atado, en quarto, en que están una librança de Pedro de Pedraça, administrador del hacienda del conde $/{ }^{39 v}$ de Aguilar, para que se paguen los réditos de un censo que pagava la dicha condesa de Aguilar y otros papeles tocantes a este censo y juro de las salinas.

219. Otro legajo de cartas misivas de diferentes personas.

220. Otro legajo atado, en quarto, en que están la memoria desde quando partió de Madrid Francisco Arias del Castillo a Campotéjar y otros papeles tocantes al dicho Campotéjar y al dicho Francisco Arias del Castillo.

221. Un librillo de quince ojas scritas de letra de Sebastián Romero en que están inventariados todos los bienes del dicho señor marqués. 
222. Otro inventario, autoriçado ante Melchor Cisneros scrivano, de los vienes que recibió Francisco del Castillo en la ciudad de Granada en las [...] del dicho señor marqués en el quarto de las frutas.

223. Otro inventario de los vienes que quedaron por muerte de la señora doña María de Velasco y Venavides.

224. Raçon de la quenta de los cien mill maravedís de por vida.

225. Raçón de los alcançados de Pablo del Castillo.

226. Otro atado, en forma de memoriales, en que está el testamento de la señora doña María de Velasco, mujer del dicho señor marqués, y cartas de pago.

Todos los quales dichos papeles se volvieron a meter en el dicho cajón.

Y se abrió un segundo cajón y en él se allaron los papeles siguientes:

227. Un libro enquadernado con cubiertas de badana que dice con letras doradas encima "previlejio de la villa de Jaiena".

228. //40r Otro libro como el passado que dice en las letras doradas "previlejio de la villa de Campotéjar".

229. Otro libro como los passados, pendiente un sello de plomo, que es el previlejio de Campotéjar y Jaiena.

230. Otro libro con cubierta de pergamino que dice "carta de venta de las tierras que compró el señor don Pedro de Granada en el pago de Piçarrama".

231. Otro libro de pergamino, la cubierta dice "escritura de censo que paga don Rodrigo de Herrera de mill ducados de principal".

232. Otro libro con pergamino, de folio, que es el título de la composición del monte de Santa Polonia.

233. Otro libro, atado con una trancadera, que es el censo de la dote de mi señora la marquesa, que paga el duque de Alva del dote de mi señora la marquesa. (Al margen): Censo del duque de Alva.

234-235. Otro libro con cubierta de pergamino y un legajo de papeles que están en él, doblados en quarto, atados con una trancadera, todos son previlejios y papeles tocantes a las alcabalas de Campotéjar. (Al margen): Alcavalas de Campotéjar.

236-237. Otro legajo de papeles atados, en quarto, y un libro de pergamino, en folio, que todo está atado con una trancadera, que son los títulos y papeles de la cassa principal junto a San Nicolás.

238. Otro legajo de papeles atados, en quarto, cubierto con un papel de estraça, que son los títulos del juro de tres mill ducados de principal sobre puertos secos del dote mi señora la marquesa. (Al margen): Juro de puertos secos.

239. Un legajo de papeles atado, en quarto, tocante a Francisco López Cavallón.

240. Otro legajo de papeles atado, en quarto, que son cartas misivas de Campotéjar del año de seiscientos y treinta y uno.

241. Un libro en folio, de pergamino, que son los reconocimientos que hiço el conde de Colmenar de los dos censos de seis mill ducados que están sobre los molinos del Aldegüela.

242. // 40v Un legajo de cartas misivas, atadas, en folio.

243. Una requisitoria de pago contra el conde de Colmenar y reconocimiento de los dichos censos de los molinos del Aldegüela.

244. Un papel doblado, en quarto, que dice "Cañavate", es de Alonso Martínez de Piqueras.

245. Otro papel doblado, en quarto, que dice "libro del quinto de la renta de trigo y cebada y semillas de la villa de Jaiena, cobrado por Diego Ximénez el año de seiscientos y cuarenta y uno".

Todos los quales dichos papeles se bolvieron a meter en el dicho cajón. 
Y en el [quarto] cajón se allaron los papeles siguientes:

246. Un legajo de cartas misivas de Jaiena y Campotéjar del año de seiscientos y treinta y ocho.

247. Otro legajo atado, en quarto, de cartas y cosas tocantes a Juan de Suescun.

248. Otro legajo de papeles y cartas tocantes a Jayena de las causas y daños que se an echo en ella por diferentes personas de talas y otras cosas.

249. Otro legajo de papeles atado, en quarto, en que ay cartas tocantes a Jayena y las rentas de pan y precios a que se a vendido.

250. Otro legajo de papeles tocantes a don Pedro Masquefa.

251. Otro legajo de papeles y cartas tocantes a Diego Ximénez de Jaiena.

252. Otro legajo de papeles tocantes a Juan de Suescun del tiempo que fue maiordomo.

253. Otro legajo de papeles tocantes a Jaiena y su partido y de Santa Polonia y el suio.

254-255. Otro legajo de papeles en que están unos papeles doblados en quarto, que el primero es una memoria de las deudas que deven al dicho señor marqués, y una información de las iuntas que se an arrendado en la villa de Campotéjar y aran en ella.

256. //41r Otro legajo de papeles en que están los papeles del descargo de la quenta que tomó Antonio de Lossada.

257-258. Otro legajo de papeles en que está la scriptura de Juan López y su muger y otro traslado del repartimiento de los marjales de tierra de riego de Jaiena.

259. Otro legajo en que están los papeles tocantes a la capellanía del hacienda de Nerja.

260. Otro legajo que es la requisitoria contra Josep Montes.

261. Otto legajo de papeles atado, en forma de memorial, que dice "Jaiena".

262. Otro legajo doblado, en quarto, que es raçón de la renta del trigo y cevada de la villa de Jaiena y Santa Polonia del año de seiscientos y quarenta.

263. Otro legajo de papeles en que está el tanteo de quenta que se hiço a Diego Ximénez y las obligaciones que el susodicho y su muger hicieron para la maiordomía de Jaiena.

264. Otro legajo de cartas de Francisco Arias del Castillo del año de seiscientos y treinta y siete.

265. Otro legajo de papeles tocantes al cortijo de Corçola.

Todos los quales dichos papeles se volvieron a meter en el dicho cajón quarto.

Y en el quinto cajón se allaron los papeles siguientes:

266. Un legajo de cartas de diferentes personas del año de seiscientos y quarenta y dos.

267. Otro legajo de cartas del año de quarenta.

268 Otro legajo de cartas del año de quarenta y uno.

269. Otro legajo de cartas del dicho año.

270. Un legajo de papeles tocantes al Cañavate y a la quenta con don Gregorio de Briones, el conde de Colmenar, y Alonso Martínez de Piqueras.

271. Otro legajo de papeles tocantes a la tercera parte de Veamud, que es del mayorazgo.

272. Otro legajo de papeles tocantes a los molinos de Peñaquebrada y hacienda de Alarcón, en que está un traslado de la scriptura de fundación del pósito de //41v Veamud y otros papeles de don Ramón Pallas.

273. Otro legajo de cartas del año de seiscientos y quarenta y dos.

274. Otro legajo de papeles tocantes a la quenta de Antonio de Losada en Cuenca.

275. Otro legajo de papeles tocantes al pleito de Veamud y quentas de Pedro Díaz de la Torre.

276. Otro legajo de papeles tocantes a la quenta que dio Sebastián Romero quando estubo en Cuenca y para averiguar la muerte de Gonçalo García. 
277. Otro legajo de papeles de la quenta y cartas de pago del censo de Colmenar hasta el año de seiscientos y treinta y quatro.

Todos los quales dichos papeles se volvieron a meter en el dicho cajón quinto.

Y se allaron en el sexto cajón los papeles siguientes:

278. Un legajo de papeles agujereados que es un tanto de la quenta de Francisco del Castillo.

279. Otro quaderno tocante al quarto de Carnafate del año de seiscientos y treinta y seis.

280. Otro legajo de papeles tocantes a la maiordomía de Jaiena de Juan Luis de Figueroa.

281. Papeles de quentas y otras cossas tocantes a Melchor de Rivas y Blas de Martos.

282. Otro legajo de papeles y memoriales tocantes al pleito con don Francisco Centurión.

283. Otro legajo de papeles que es la scritura de dote y arras de la señora doña María de Mendoça quando cassó con don Diego Ruiz de Alarcón.

284. Otro legajo de cartas de diferentes personas del año de seiscientos y quarenta y dos.

285. Otro legajo de papeles tocantes a Francisco de Rivera del tiempo del gobierno de Jaiena.

286. Otra requisitoria contra el susodicho por el alcance de la dicha mayordomía.

287. // ${ }^{42 r}$ Otro legajo de papeles de la quenta que dio Sevastián Romero de Cuenca, Belmonte, Cañavate y Beamud.

288. Otro legajo de papeles tocantes al censo de don Jaime Pallas.

289. Otro legajo de papeles tocantes al pleito y hacienda de Cuenca y Beamud.

290. Otro legajo de papeles doblado, en forma de memorial, tocante a la obligación y quenta de Alonso Martínez de Piqueras, maiordomo del Cañavate.

291. Otro legajo de cartas de diferentes personas del año de seiscientos y quarenta y uno.

292. Otro legajo de cartas del año de seiscientos y quarenta y dos.

Todos los quales dichos papeles se volvieron a meter en el dicho cajón.

Y se allaron en el sétimo [cajón] los papeles siguientes:

293. Un legajo de papeles tocantes a la quenta de Peñarroja y procesos contra Francisco García, ventero, y Juan de Lomas, su fiador.

294. Otro legajo de papeles en que está una scriptura de transacción entre los señores don Luis Fernández de Córdova y don Alonso de Granada Venegas sobre la obra de la capilla de San Francisco de Granada.

295. Otro legajo de papeles tocantes a Blas de Martos en que ay cartas y scripturas de obligación suias.

296. Otro legajo de papeles de a folio y otros de a quarto, atados todos juntos, que son tocantes a la quenta de don Jacinto de Rivera, maiordomo que fue del hazienda de Campotéjar y Granada.

297. Otro legajo de papeles tocantes a Lope Fernández de Contreras del hacienda y maiordomía de Granada.

298. Otro legajo de papales tocantes a Juan de Lomas y Peñarroja.

299. Otro legajo de papeles tocantes a Jeneralife y sus reparos.

300. Otro legajo de papeles de Campotéjar tocantes al licenciado Delgado.

301. //42v Otro legajo de cartas de pago de lo que se pagó del censo de la memoria [del canón]igo Barreda, que tomó el señor don Fernando de Granada con poder del dicho señor marqués.

302. Otro legajo de cartas y papeles tocantes al hacienda de Granada. 
303. Otro legajo que es recivo ante scrivano de lo que está en la torre de las cassas principales de Granada.

304. Otro legajo en forma de memoriales, que son cartas de pago de quentas de don Jacinto de Rivera.

305. Otro legajo de papeles en que está una cédula de su magestad para que las justicias de Jaiena puedan salir de su jurisdición en seguimiento de los pressos.

306. Una carta de pago de la Yglesia de Granada de och[...] ducados.

307. Otras cartas del señor don Fernando de Granada y don Juan de Granada.

Todos los quales dichos papeles se volvieron a meter en el dicho cajón y se cerró el dicho escritorio.

Y se abrió otro scritorio de nogal enbutido que tiene nueve cajones y en el primero se allaron los papeles siguientes:

308. Un libro enquadernado en tablas de becerro que es la scriptura de censo de veinte mill ducados sobre los propios de la ciudad de Toledo, de que pertenecen al dicho señor marqués los diez mill de ellos.

309. Más otro libro de pergamino doblado y papeles en quarto que son tocantes al dicho censo y remate que se an echo de él por diferentes executorias a pedimiento del señor marqués.

Los quales dichos papeles se volvieron a meter en el dicho cajón.

Y se abrió otro cajón segundo y en él se allaron los papeles siguientes:

310-312. Un legajo atado, en folio, de papeles tocantes al censo de los quatro mill ducados de Buenache y la executoria de la tercera parte de Beamud y reconocimiento de doña Luisa de Cárdenas, y una executoria contra don Jaime //43r Pallas que está en un libro de pergamino de a folio.

313. Un legajillo de cartas de pago, doblado, en forma de memorial, que trujo la señora doña Mariana de Granada, día de Todos Santos de [...].

314-315. Otro legajo de papeles doblados en que están algunos tocantes a Buenache y el testamento de don Juan Ruiz de Alarcón.

316. Otro legajo de papeles doblados tocantes a Beamud.

317. Otro legajo de papeles doblados que son obligación de Andrés de Alarcón y otra obligación de Martín López Cavallón.

318. Otro legajillo de papeles de cartas de pago de letrados y scrivanos del pleito de Buenache.

319. Otro legajo de cartas de pago.

320. Otro legajillo de memoriales y quenta de Eujenio Álvarez.

321. Otro memorial de los servicios de la Cassa.

Todos los quales dichos papeles se volvieron a meter en el dicho cajón.

Y se abrió el tercero cajón y en él se allaron los papeles siguientes:

322. Un legajo, doblado en quarto, que son los traslados simples de cédulas y cartas y servicios del señor don Alonso de Granada 2 de la Cassa.

323. Otro legajo de papeles de Pablo del Castillo, de poca inportancia.

324. Otro legajo de papeles, traslados sinples tocantes a los servicios del señor don Pedro de Granada el primero

Todos los quales dichos papeles se volvieron a meter en el dicho cajón.

Y en el quarto se allaron los siguientes:

325. Un legajo de papeles tocantes a la partición de don Jinés de Carrança y mi señora doña Aldonça Renjifo y quenta de Gómes de Castillo.

326. Otro legajo de papeles, doblado en quarto, donde está el testamento del señor don Gerónimo de Granada y otros papeles tocantes al susodicho. 
327. Otro legajo de papeles que es una carta executoria de la Chancillería de Granada para cobrar de la hacienda de la marquesa de Estepa y sus fiadores cinco mill ducados.

328. Otro legajo de papeles de cartas de pago y escrituras del año de 595.

329. Otro legajo de papeles como el passado de cédulas de dineros pagados del año de 1586 .

330. Otro legajo de papeles en que está una memoria del hacienda de la Cassa de Granada.

331. El título original para que el señor marqués sirva el oficio de alguacil maior de Granada por la menor edad de don Luis Maça.

$/ /{ }^{43 v} \mathrm{Y}$ en el quinto cajón se allaron los papeles siguientes:

332. Dos sellos de cerrar cartas con las armas de Granada y Mendoça.

333. Otro legajo, en forma de memorial, de dineros y cartas de pago del año de mill y quinientos y ochenta y cinco.

334. Otro legajo de papeles tocantes a Salobreña.

335. Otro legajo de cartas de don Juan de Palma.

Todos los quales papeles se volvieron a meter en el dicho cajón.

Y se abrió el sexto y en él se allaron los papeles siguientes:

336-337. Un legajo cubierto con papel de estraza con las scripturas de censos perpetuos y otros recaudos, y una volsa de lienço con los títulos del mayorazgo del comendador Gil Vázquez Renjifo.

Todos los quales papeles se volvieron a meter en el dicho cajón.

Y se abrió el sétimo y en él se allaron los siguientes:

338. Un legajo en que están los títulos de [compra] de los esclavos.

339. Otro legajo de papeles de poca importancia.

Todos los quales dichos papeles se volvieron a meter en el dicho cajón.

Y se abrió el otavo y en él se allaron los siguientes:

340. Un legajo de papeles donde están los títulos orijinales de las cassas principales del mayorazgo que instituió el señor don Alonso Venegas y el señor don Pedro y los demás papeles tocantes a ello, atados con un cordón de seda negra.

Todos los quales dichos papeles se volvieron a meter en el dicho cajón.

$\mathrm{Y}$ en el noveno se allaron los siguientes:

341. Un legajo en forma de memorial que no vale nada.

Y se volvió a meter en el dicho $/ / 44$ cajón y se cerró el dicho scritorio.

Abriose otro scritorio de évano y marfil de doce cajones con una alacena y en él se allaron los papeles siguientes:

342. En el alacena un legajo de papeles que son cartas de pago de salarios y otras cosas de diferentes personas.

343. Otro legajo de papeles que es la quenta con el [...].

344. Otro legajo de cartas de pago de avogados y relatores y de procurador y de doña Antonia de Solórzano y otras personas.

Abriose otro cajón y en él se allaron los siguientes:

345. Un legajo de papeles, doblado en quarto, en que están algunas memorias de los vienes de Jeneralife y cartas de pago, de gastos y obligaciones de algunos tenientes.

346. Otro legajo de papeles tocantes al pleito de Pablo del Castillo.

347. Otro legajo de papeles del pleito del dicho Castillo en que está una carta de pago del licenciado Durante, relator de dicho pleito.

348. Otro legajo de papeles tocantes al dicho Pablo del Castillo.

Abriose otro cajón y en él se allaron los papeles siguientes:

349. Un traslado del nombramiento de alcaide de Jeneralife en don Alonso de Granada. 
350. Otro traslado de cédulas de su magestad tocantes a la guarda de Jeneralife y sus términos.

351. Otro legajo en que está la información sobre la recompensa de la güerta de Jinarjo, que era de Jeneralife.

352. Otros traslados de cédulas reales de Jeneralife.

353. Otra scriptura de traspaso que hiço doña Juana del Aceituno, viuda de don Francisco Alfaro, en Jeneralife.

354. Traslado del pleito sobre la jurisdición de Jeneralife.

355. //44v Traslados de los títulos del alcaidía de Jeneralife.

356. Otro legajo de papeles tocantes a la jurisdición de Jeneralife en que está una provança que hicieron los frailes de los Mártires.

357. Traslado autoriçado de la facultad que tienen los alcaides de Jeneralife para nombrar guardas.

358. Recivo de Pedro de Villanueva, oficial de la secretaría de Obras y Bosques de los papeles de gastos echos en Jeneralife.

359. Otro legajo de peticiones tocantes a la jurisdición de Jeneralife.

360. Planta del sitio de Jeneralife.

Todos los quales dichos papeles se volvieron a meter en el dicho cajón.

Y se abrió el quarto cajón y se allaron en él los papeles siguientes:

361. Un título orijinal scrito en pergamino de marqués de Campotéjar despachado en caveça del dicho señor marqués, el qual acavó de despachar en toda forma mi señora la marquesa después de su muerte.

362. Una scriptura de fundación de una capellanía de la señora doña Catalina de Venavides.

363. Testamento de mi señora doña María de Ochoa, que es traslado autoriçado ante Bernardo Ruiz de Prado.

364. Un traslado simple del título de la scrivanía de la ciudad de Alcaraz.

365. Otro legajo de papeles en que están el aviso y dispusición de la muerte del padre fray Leandro.

366. El testamento y codicilo de la señora doña María Manrique.

367. El testamento del señor don Diego de Granada.

Los quales dichos papeles se volvieron a meter.

Y se abrió el quinto cajón y se allaron los papeles siguientes:

368. // ${ }^{45 r}$ Un legajo de papeles doblados, en quarto, en que están diez scrituras de obligación echas en favor del dicho señor marqués por diferentes personas.

369. Otro legajo de papeles y cartas de poca importancia.

370. Cédula de su magestad para que a la parte del capitán don Antonio Pérez de Bustamante se le pague lo que se le deviere de su sueldo.

Todos los quales dichos papeles se volvieron a meter en el dicho cajón.

Y se abrió el sexto y se allaron en él los papeles siguientes:

371. Un legajo atado, en quarto, en que están las scrituras de concierto entre el dicho señor marqués y Juan Láçaro, maestro de obras, sobre la nueva obra del quarto nuevo.

372. Otro legajo de cartas de pago de Juan Láçaro.

373. Otro legajo de cartas de pago que dio el dicho Juan Láçaro, que están pasadas en quenta en la que dio hasta el año de 1625.

374. Otro legajo de cartas de pago del carpintero que hiço las ventanas y del albañir que tejó los tejados de la cavalleriça.

Todos los quales dichos papeles se volvieron a meter en el dicho cajón.

Y se abrió el sétimo y en él se allaron los papeles siguientes: 
375. Un legajo de papeles tocantes a Ramón.

376. Una fiança de Juan de Palaçios y otros memoriales de los servicios del marqués.

Los quales dichos papeles se volvieron a meter en el dicho cajón.

Y se abrió el otavo y en él se allaron los siguientes:

377. Un traslado autorizado de los retratos que están en la Quadra Dorada de los Reyes en la cassa de Granada de los Tiros.

Los quales dichos papeles se volvieron a meter en dicho cajón.

// ${ }^{45 v}$ Y se abrió el noveno, y no uvo papeles en él.

Abriose el décimo cajón y en él se allaron los papeles siguientes:

378. Un legajo de papeles tocantes al oficio de alguacil mayor de Granada.

379. Un scriptura de obligación echa por Francisco Vereas y Francisco Prieto, vecinos de Trillo, para unas puertas de las casas principales.

380. Un legajo de papeles de poca inportancia tocantes a Güétor.

381. Otro traslado de la sentencia de Güétor dada en Granada..

382. Otro legajo de los traslados de scripturas tocantes a Güétor.

Todos los quales dichos papeles se volvieron a meter en dicho cajón.

Y se abrió el undécimo cajón y en él se allaron los siguientes:

383. Un legajo de traslados de las cartas del emperador para el señor don Alonso de Granada Venegas.

384. Un legajo de papeles en forma de memorial en que están algunas cédulas de obligación de Sevastián Romero y recivo de dinero de otras personas.

385. Otro legajo doblado, en quarto, en que está el traslado de los letreros de los reyes que están en la Quadra de la cassa de Granada.

386. Otro legajo de papeles doblados, en forma de memorial de la quenta con Fernando Suárez quando vino de Cuenca.

387. Otro legajo de cartas de pago, doblado, en forma de memorial, pasadas en quenta del año de 1621.

388. La posesión del estado de Varrientos que se tomó por don Pedro Ruiz de Alarcón.

Todos los quales dichos papeles se volvieron a meter en dicho cajón y se cerró.

$\mathrm{Y}$ en este estado se quedó el dicho inventario para proseguir en él adelante. Testigo (ilegible) Doy fe, ante mí, Antonio de Carvajal (rubricado).

// ${ }^{46 r}$ (Al margen): Prosigue el inventario.

En la villa de Madrid, a cinco de março de mill y seiscientos y quarenta y tres años, ante mí el dicho scrivano, la parte de los dichos testamentarios del dicho marqués de Campotéjar prosiguieron el dicho inventario de vienes de dicho señor en la forma y manera siguiente.

Abriose otro scritorio de évano y marfil que tiene onçe gavetas y en la primera se allaron los papeles siguientes:

389. Una carta de pago del licenciado Morales Ballesteros de ducientos reales de su salario.

390-392. Otro legajo de papeles en forma de memorial donde están dos memoriales, uno pediendo lo que debe don Luis de Villagutierre y otro el despacho del título de marqués, y revocación del salario del doctor Cerrato.

393. Carta de don Luis Ramírez de Arellano y lo que debe de ella.

394. Cédula orijinal de su magestad para dar a censo perpetuo las tierras de Campotéjar y Jaiena y casas.

395. Carta de pago de mill y trecientos ducados que otorgó el señor don Xil Renjifo a quenta de la dote de mi señora doña María Manrique ${ }^{66}$.

66. Error, por María Guillén. 
396. Otro legajo de cédulas y scripturas // ${ }^{46 v}$ de obligación de Pedro Serrano y Juan de Aguilera.

397. Una cédula de noventa y cinco reales que debe el licenciado Meneses.

398. Un testimonio del depósito de los ducientos ducados para tomar la casa de la calle del Arenal.

399. Una obligación de don Matheo de Rojas y su mujer de dar quenta con pago de lo que se le entregare.

400. Scriptura de obligación que otorgaron Pedro Fernández de Palma y su mujer de dar quenta con pago de lo que se le entregare.

401. Tres cartas de pago de Blas Muñoz de Ramos de mill y trecientos y treinta y dos reales.

402. Obligación de Pedro Masquefa de dar quenta con pago.

Todos los quales dichos papeles se volvieron a meter en la dicha gaveta.

Y se abrió la segunda y en ella se allaron los papeles siguientes:

403. Una carta de pago de mill y trecientos reales de Andrés Chico, panadero de casa.

404. Scritura de la maiordomía de Christóval de Acevedo.

405. Un legajo de papeles presentados en la Cámara para el despacho del título del señor marqués.

406. Scriptura de obligación de Nicolás López, vezino de Güétor.

407. Un legajo de papeles y cartas de los reyes scritas al comendador don Jil Vázquez Renjifo.

408. Memorial remitido a la Junta de Casa del Aposento.

Todos los quales dichos papeles se volvieron a meter en la dicha gaveta.

Y se abrió la tercera y en ella se allaron los papeles siguientes:

409. // ${ }^{47 r}$ Un legajo de papeles doblados, en quarto, en que ay algunas obligaciones de criados y otras de poca importancia.

410. Otro legajo de papeles en que están el recibo de los arcabuces y mosquetes del socorro de Adra.

411. Una scritura de arrendamiento de Toribio Martín.

412. Carta de pago del señor don Juan de Granada de ciento y veinte y cinco fanegas de trigo.

413. Y otras cartas de pago.

414. Otro legajo doblado de cartas de pago de diferentes personas.

415. Revocación de salario de don Esteban de Prado y otros papeles.

Todos los quales dichos papeles se volvieron a meter en el dicho cajón.

Y se abrió el quarto y se allaron los papeles siguientes:

416. Un legajo de papeles de cartas de pago de las lanças pagadas por Francisco del Castillo.

417. Remate de quenta con Juan de Criales, mercader.

418. Carta de pago de los ducientos ducados que pagó el señor marqués de donativo.

419. Carta de pago de catorce mil reales de las lanças del señor marqués de Monasterio.

420. Un recibo de las prendas del conde de Grajal.

421. Obligación de Manuel López de Salcedo para el despacho del juro de millones.

422. Papeles tocantes a las prendas de don Francisco Luis de Alencastre.

423. Otro legajo de cartas de pago de las lanças.

424. Carta de pago de Andrés Chico de tres mill reales.

425. Una carta del rey para el dicho señor don Pedro.

426. Carta de pago de don Juan Porcel, soldado montado.

Todos los quales dichos papeles se volvieron a meter en el dicho cajón. 
Y se abrió el quinto y en él se allaron los papeles siguientes:

427-430. Un legajo de scripturas de obligación de diferentes personas, en que ay quatro scripturas.

431. Remate de quenta con Láçaro Midense, ginovés.

432. Traslado autorizado de una cédula de su magestad en reçagos de millones.

433. Cédula de Juan de Luján en que se obligó a pagar al señor marqués ciento y veinte reales.

Todos los quales dichos papeles se volvieron a meter en la dicha gaveta.

Y se abrió la sexta y en ella se allaron los siguientes:

434. // 47v Una scriptura de reconocimiento que hiço el señor don Jil de Granada para que cada y quando que el dicho señor marqués quisiese renunciar el oficio de veinte y quatro de Granada en Casa ( $\mathrm{sic}$ ), que se ponga en su caveça.

435-441. Seis legajos de consultas del Bureo y otro en forma de memorial de lo mismo.

442.Y otros memoriales tocantes al Bureo y oficiales de la Casa de la reina nuestra señora.

Los quales se volvieron a meter en la dicha gaveta.

Y se abrió la sétima y se allaron en ella los papeles siguientes:

443-444. Un traslado del título de la scrivanía de las ciudad de Alcaraz y poder a Francisco de Solís.

445-446. Certificaciones del grafiel de como el señor marqués juró de maiordomo de la reina nuestra señora, y de lo que se le deve de los gajes de jentilhombre.

447. Executoria contra el capitulante del correjimiento de Ávila.

448. Una scritura de redención de censo de los quinientos ducados que se tomaron de las memorias del canónigo Barreda, que la mitad redimió Antonio Ruiz de la Peña.

449. Y la otra mitad Melchor de Ervias.

450. Un legajo de cartas de pago de diferentes personas.

451-452. Otro legajo de obligaciones del señor don Xil de Granada, la una de siete mill novecientos y setenta y un reales, su fecha en quince de junio de mill y seiscientos y treinta y tres ante Diego de Ledesma, la otra de mill reales para acavar de cumplir el ávito de Santiago.

453-455. Más una cédula de los vienes que le quedaron en guarda, respuesta de la demanda que puso el señor don Xil y auto para que el scrivano vaya a hacer relación.

456. Una cédula del señor don Xil de los vienes muebles que quedaron en su poder para volvellos // ${ }^{48 r}$ quando se le pidan.

457. Otro legajo de cartas de pago de diferentes personas.

458. Una cédula de doce ducados a don Diego de Alarcón, que después hiço scriptura.

459. Otro legajo de papeles que entregó el licenciado Pedro Díaz de la Torre quando fue a Cuenca, en que está la quenta con Juan Acedo Velazquez de lo que se le pagó.

460. Otra de don Juan de España.

461. Otra de don Bicencio Cañiçares.

462. Otra provisión de su magestad contra Diego Pollino.

463. Una carta de pago de Juan de Frías, platero, de la cantinplora y cubo que se le compró y fee del contraste de lo que pesó.

464. Carta de pago de don Francisco Guillamas al pie de una obligación del señor marqués.

Todos los quales dichos papeles se volvieron a meter en la dicha gaveta.

Y se abrió la otava y en ella se allaron los papeles siguientes:

465. Un legajo de consultas del Bureo. 
466-467. Un legajo de papeles en que está una scritura del concierto entre el señor don Diego y don Juan de Granada, y carta de pago del licenciado Rojas Calderón.

468. Otro legajo de papeles de quentas menudas con algunos criados.

469. Otro legajo de papeles tocantes al Bureo.

Todos los quales dichos papeles se volvieron a meter en la dicha gaveta.

Y se abrió la última y en ella se allaron los papeles siguientes:

470. Traslado del ávito del señor don Alonso de Granada.

471. Los títulos del alcaidía de Nerja.

472. El concierto echo con el padre fray Torcuato Ortiz sobre le herencia del padre fray Leandro.

473. Testimonio orijinal que dio el señor Gregorio de Tapia del // ${ }^{48 v}$ del auto del Consejo de Órdenes en virtud de la consulta y otros papeles.

474. Traslado de la scritura de concierto que hiço el señor don Juan de Alarcón sobre la dehesa de Torralva.

475. Testimonio de como tiene dada carta de pago Catalina de Canseco de los ochocientos cincuenta y quatro mill quatrocientos y quarenta maravedís.

Todos los quales dichos papeles se volvieron a meter en el dicho scritorio y se cerró.

Abriose una arquilla de pino y en ella se allaron los papeles siguientes:

476. Una carta executoria de la Chancillería de Valladolid entre doña María Guillén y Mencía Ortiz, su madre, sobre las güertas del Arroio de junto a Atocha.

477. Partición de la dicha Mencía Ortiz entre sus hijos.

478. La scritura y carta de venta de la güerta primera del valle de Atocha, que se otorgó en favor de don Diego Baçán con cargo del censo perpetuo y veintena al maiorazgo del señor don Pedro de Granada.

479. Un libro de reconocimientos de los censos perpetuos de las güertas del valle de Atocha.

480. Otro libro en que está el maiorazgo que fundó en su testamento el señor Gómez Guillén.

481. El patronazgo de la capilla de San Xinés.

482. Y las cassas de la calle del Arenal.

483. Y las güertas del valle de Atocha.

484. Otro libro en que está la scriptura de transacción que se hiço por la señora Mencía Ortiz entre $/ /{ }^{49 r}$ sus hijos de primero y segundo matrimonio.

485. Otro libro de quarto, de pergamino, con una cinta de cuero, en que están escritas algunas ojas de las quentas de las güertas y demás hacienda tocante al maiorazgo que fundó el señor Gómez Guillén.

486. Un legajo de papeles, de folio, en que está la partición primera que se hiço de los vienes del señor Gómez Guillén entre Mencía Ortiz y doña María Guillén, su hija mayor.

487. Y otras particiones tocantes a los susodichos.

488. Otro legajo de papeles atado, en quarto, en que están scrituras de ventas y otras lijitimaciones de las güertas y hacienda tocantes al maiorazgo del señor Gómez Guillén.

489. Otro legajo atado, en quarto, que dice "relación para el señor don Fernando de Villafañe, tocante al hacienda de Madrid conforme al testamento de la señora Mencía Ortiz".

490. Otro legajo de papeles atado, en quarto, en que están las quentas y arrendamientos del hacienda de Madrid del tiempo que la goçaron don Xinés de Carranza y doña Aldonça Renjifo, su muger.

491. Otro legajo de papeles doblado, en quarto, en que están las quentas tocantes al hacienda de Campotéjar de Pablo del Castillo. 
492. Otro legajo de papeles atado, en quarto, en que están las obligaciones que hiço Pablo del Castillo y otras quentas y papeles tocantes al susodicho.

493. Un legajo doblado, en folio, en que están los borradores de las quentas de Pablo del Castillo.

494-495. Un legajo de papeles en que está un libro encuadernado y otros papeles sueltos con una cubierta encima que dice "libro del padre fray Leandro de Granada que se a de imprimir".

496. Un libro intitulado Redención del mundo, scrito de mano.

497. Un legajo de papeles en forma de memorial $/ / 4^{49 v}$ donde está una memoria de los gastos echos por el señor don Pedro en los vienes del mayorazgo.

498. Otro librillo en quarto, de pergamino buelto, en que está la quenta de la recámara del dicho señor marqués.

499. Otro legajo de papeles atados en que están algunos autos echos contra Pablo del Castillo.

Todos los quales dichos papeles se volvieron a meter en la dicha arca y se cerró.

500-501. Y se abrió un scritorio de quatro cajones, de pino, y en el [primero] se hallaron dos legajos de cartas, el uno del año de 1629 y el otro de 1631 .

502-503. En el segundo cajón se allaron otros dos legajos de cartas, el uno del año de 630 y el otro de 634 .

504. Iten se alló en el dicho cajón un papel grande con obados de la Cassa de Granada.

505. En el tercero cajón avía una scritura de censo de dos mill ducados contra el estado de doña Luisa de Cárdenas.

506. Más un legajo de papeles tocantes a Andrés Gonçález, mayordomo que fue de Campotéjar.

507. Otro legajo de papeles y quentas de don Fernando Venegas, maiordomo que fue de Campotéjar.

508. Un legajo de cartas del año de 1634.

En el quarto cajón se allaron los papeles siguientes:

509. Un legajo de cartas del año de 1631.

510. Otro legajo de cartas tocantes a Pablo del Castillo.

511. Otro legajo de papeles y consultas tocantes al Bureo y Cassa de la reina.

512. Una requsitoria y demás papeles contra Antonio Pérez de Bustamante.

513. Traslado de las scrituras de doña Mencía Carrillo de //50r Albornoz.

514. Una provisión tocante a la paga de las salinas de Espartinas.

515. Otro legajo grande de cartas de diferentes partes del año de 1633.

Todos los quales dichos papeles se volvieron a meter en el dicho scritorio y se volvió a cerrar.

Abriose otro scritorio, de pino, con ocho cajones y en el primero se allaron los papeles siguientes:

516. Un legajo atado, en quarto, con pergamino, de papeles tocantes al censo de los diez y seis mill y quinientos ducados de Cuenca.

517. Otro legajo tocante a los arrendamientos de Jeneralife y otras cosas.

518. Otro legajo de papeles en que está una requisitoria para Ocaña y Colmenar sobre el censo de doña Luisa Carrillo.

519. Otro legajo de papeles tocante a lo mismo.

520. La quenta del señor marqués con el de Monasterio de lo que le an repartido de lanças para los presidios.

521-522. Dos peticiones tocantes al pleito del marqués de Armuña.

523. Un borrador de información en derecho sobre el pleito de Güétor. 
Los quales papeles se volvieron a meter en el dicho cajón.

Y se abrió el segundo cajón y en él se allaron los papeles siguientes:

524. Un libro largo, encuadernado, que dice "memoria de los pleitos".

525. Otro libro enquadernado de la misma manera, que es de lo tocante a Campotéjar y su partido.

526. Otro libro como los de arriva de cossas diferentes.

527. Un legajo de papeles atado, en quarto, en que están las quentas que se remataron entre el licenciado Rivera y Alonso de Villalúa / $/{ }^{50 v}$ con el señor don Pedro de Granada.

528. Otro legajo de papeles tocantes al censo de Cuenca y juro de salinas de Espartinas.

529. Otro legajo de papeles tocantes a lo susodicho.

530. Otro legajo de papeles en forma de memorial, que es la obligación del maiordomo de Cañavate y raçón de la renta.

531.Y otra quenta y carta de pago de Juan Fernández de Córdova del juro de Espartinas.

Los quales papeles se volvieron a meter en el dicho cajón.

Y se abrió el tercero y en él se allaron los papeles siguientes:

532. Un legajo de cartas de diferentes personas del año de 640 y 641.

533. Un legajo de papeles tocantes al alcaidía de Almuñécar.

Los quales dichos papeles se volvieron a meter en el dicho cajón.

$\mathrm{Y}$ en el quarto se allaron los siguientes:

534. Un legajo de cartas del año de 640 y 641 de diferentes personas.

535. Un legajo de papeles tocantes a Diego del Valle, panadero.

Los quales dichos papeles se volvieron a meter en el dicho cajón.

Y se abrió el quinto y en él se allaron los papeles siguientes:

536-538. Un legajo de papeles en que están los títulos del solar que está en la parroquia de la Iglesia Mayor de Granada en frente de las casas antiguas, y otros papeles que llevó el doctor Arjona a Granada, y la quenta de lo que costó la escalera nueba que se hiço en las casas de Madrid.

539. Una scritura de censo perpetuo que otorgó Juan García de Montiel, vezino de Campotéjar, del solar de una casa $/ /{ }^{/ 1 r}$ que hiço junto a las casas del mayorazgo.

540. Otro legajo de papeles y diligencias echas para la cobrança del censo de Toledo.

Los quales dichos papeles se volvieron a meter en el dicho cajón.

Y se abrió el sexto y se allaron en él los papeles siguientes:

541. Un legajo de cartas de diferentes personas del año de 1636.

542. Un legajo de papeles tocantes a las capitulaciones del dicho señor don Pedro con la señora doña María de Velasco.

543. Otro legajo tocante a las capitulaciones del dicho señor don Pedro con mi señora la marquesa.

544. Scritura de obligación que otorgó Tomás López, ortelano de Jeneralife.

Los quales dichos papeles se volvieron a meter en el dicho cajón.

Y se abrió el sétimo y en él se allaron los siguientes:

545-547. Un traslado de tres scrituras tocantes al dote de la señora doña María de Mendoza.

548. Un legajo de papeles tocantes a Pablo del Castillo.

549. Otro del censo de Cuenca y cartas de pago de él.

550. Traslado de una petición para el pleito del marqués de Estepa.

551. Testimonio de don Juan de Robles de como recibió un cepo y grillos.

552. Scritura de venta que otorgaron Pedro Hidalgo y María de Mendoça, su mujer, y sus hijos de Láçaro Porcel de la cómpreda del cortijo de la Canaleja.

553. Raçón de la quenta de Sevastián Romero quando fue la última vez a Cuenca. 
554. Raçón de lo que quedó a dever don Juan de Alarcón de la executoria de los ocho mill ducados.

555. Sumario del yerro de las quentas de Peñarroja.

556. Relación de los réditos que se deven del censo del marqués de Estepa.

557. Relación de lo tocante a la obra con el duque de Pastrana.

558. Carta de pago y finiquito de Manuel de Vega, scrivano del número de Santander.

Los quales dichos papeles se volvieron a meter en el dicho cajón.

Y se abrió el otavo y en él se allaron los siguientes:

559. Un legajo de cartas del año de 1636 de diferentes personas.

560-561. //51v Un legajo, atado, en rollo que son dos requisitorias del conde de Colmenar.

Los quales papeles se volvieron a meter en el dicho cajón y se cerró el dicho scritorio

Abriose otro scritorio, de pino, que tiene siete cajones y en el primero se allaron los papeles siguientes:

562. Un legajo de cartas de los años de 637, 38 y $4[\ldots]$.

563.Una memoria de la renta del señor marqués de Campotéjar.

Los quales papeles se volvieron a meter en el dicho cajón.

$\mathrm{Y}$ en el segundo se allaron los siguientes:

564. Un legajo de cartas de los años de 638, 39, 40.

565. Otro legajo de cartas de Pablo del Castillo.

566. Otro legajo de cartas del año de 1635.

Los quales dichos papeles se volvieron a meter en el dicho cajón.

Y se abrió el tercero y en él se allaron los siguientes:

567. Un legajo de cartas de los años de 638, 39 y $4[\ldots]$.

Los quales dichos papeles se volvieron a meter en el dicho cajón.

Y se abrió el quarto y en él se allaron los siguientes:

568. Un legajo de cartas del año de 1627

Los quales dichos papeles se volvieron a meter en el dicho cajón y se cerró el dicho scritorio.

Abriose una arca grande de pino y en ella se allaron los papeles siguientes:

569. Un libro grande, de a folio, en que está la raçón de toda el hacienda de señor marqués.

570. Otro libro, de pergamino, del hacienda de Granada del año de 631.

571. Otro libro como los susodichos del cargo y descargo desde que partió de esta Corte Francisco del Castillo tocante a sus quentas.

572. //52r Otro libro de lo mismo tocante al hacienda, cargo y descargo de mayordomos del año de 638.

573. Otro libro grande, de pergamino, con dos botones, en que tenía el señor marqués la raçón de toda su hacienda.

574. Otro libro viejo, largo, de cuenta desde el año de 613 hasta el de 628.

575. Otro libro, largo, de asientos de criados.

576. Otro libro, de a quarto, de asientos de criados.

577. Otro libro de entradas y salidas de dineros y raçón del hacienda.

578. Otro libro de la raçón del hacienda de Granada y Campotéjar.

579. Un enboltorio de papeles con un cuero en que están los papeles tocantes a la antigüedad de la Cassa de Granada.

580. Un pleito de Luis Carrillo de Albornoz con doña Mencía, su hija.

581. Un quaderno del testamento y codicilos del emperador Carlos Quinto.

582. Memorial del pleito sobre la taha de Marchena. 
583.Un pleito executivo del señor marqués contra don Juan de Alarcón, señor de Buenache.

584. Otro legajo de papeles contra el dicho don Juan de Alarcón.

585. Una requisitoria de pago contra los bienes de Onofre de Acevedo.

586. Mayorazgo que fundó doña Inés de Varrientos en doña Mencía Carrillo.

587. Y las scrituras de arras y dote de mi señora doña María de Mendoza al tiempo que se casó con don Diego Ruiz de Alarcón, señor de Buenache.

588. Requisitoria por trecientos ducados contra don Bernardino de Cárdenas.

589. Requisitoria contra don Francisco Centurión de mill y quinientos y cincuenta ducados.

590. //52v Una scritura de transación con mi señora doña María de Ochoa.

591. Un tanto del menaje de casa que quedó en Granada.

592-593. Otro legajo de papeles tocantes a la Cassa y un traslado de la scritura de concierto entre la señora doña María Ochoa y el señor marqués.

Todos los quales dichos papeles se volvieron a meter en la dicha arca y se cerró.

Abriose una arquilla pequeña y en ella se allaron los papeles siguientes:

594. Un legajo de papeles y quentas de mi señora doña María de Venavides.

595. Otro legajo en que está un traslado del consentimiento del Reino para el oficio de alguacil mayor de Granada y otros papeles tocantes al dicho oficio.

596. Otro legajo atado en la misma forma de cartas de pago antiguas.

597. Otro legajo en que está una scritura de don Luis Zapata Osorio de noventa y seis escudos de oro.

598. Otro legajo en que están los papeles que se llevaron a Roma tocantes a la dispensación de los ávitos.

599. Otro legajo de cartas de Granada y Jaiena.

600. Un libro del gasto y entradas y salidas del dinero del año de 1590.

Todos los quales dichos papeles se volvieron a meter en la dicha arquilla y se cerró.

Doy fe, ante mí, Antonio de Carvajal (rubricado).

\section{BIBLIOGRAFIA}

ÁLVAREZ NOGAL, C. "El Factor General del Rey y las finanzas de la Monarquía Hispánica", Revista de Historia Económica, XVII (otoño-invierno 1999), pp. 507-539.

ÁLVAREZ MÁRQUEZ, C., GARCÍA LUJÁN, J.A. "Las lecturas de don Pedro de Granada Venegas, I marqués de Campotéjar (1559-1643), Historia, Instituciones, Documentos, 35 (2008), pp. 149-189.

BALTANÁS, H. "Los molinos de la presa de la Aldehuela (Colmenar de Oreja): obras de remodelación de un complejo hidráulico en el río Tajo (siglos XVIXVII", en Actas del segundo congreso nacional de Historia de la Construcción, Coruña, 1998, pp. 35-39.

BUSTOS Y BUSTOS, A. de, Marqués de Corvera. Guerra y sitio de Baza en el siglo XV y Breve estudio del tratado de don Fernando el Católico, rey de Castilla y Aragón, con Yahia Alnayar, antes príncipe Cidi Hiaya, en lo que se refiere a la Grandeza a favor del mismo reconocida. Granada, 2008, GARCÍA LUJÁN, J.A. Estudio introductorio a la edición facsímil. 
CALERO PALACIOS, C., PEINADO SANTAELlA, R.G. "Fuentes para el estudio de la nobleza y los señoríos del Reino de Granada: el inventario del Archivo del Marquesado de Campotéjar (1682)", Revista del Centro de Estudios Históricos de Granada y su Reino, 2a época, 1 (1987), pp. 239-260.

FORTEA PÉREZ, J.I. "De nobles, lanzas y presidios", en FRANCH BENAVENT, R. y BENITEZ SÁNCHEZ-BLANCO, R. (eds.) Estudios de historia moderna en homenaje a la profesora Emilia Salvador Esteban, Valencia, 2008, vol. I, pp. 189-212.

GARCÍA LUJÁN, J.A. "Don Pedro de Granada Venegas, I marqués de Campotéjar (1643), de Campo Rey y Vizconde de Miravalles (1632), en VII Simposio Internacional de Mudejarismo. De mudéjares a moriscos: una conversión forzada, Teruel, 2002, vol. II, pp. 721-740.

—. "De heráldica granadina. El linaje Granada Venegas, marqueses de Campotéjar", en MARSILLA, F. (coord.) Littera Scripta in honorem Prof. Lope Pascual Martínez, Murcia, 2002, vol. I-1, pp. 361-378

- Genealogía y heráldica nobiliarias. La Casa Ducal de Pastrana, Córdoba, 2004.

—. Testamentos de don Pedro y don Alonso de Granada Venegas", en CALERO PALACIOS, M.C. et al., Homenaje a María Angustias Moreno Olmedo, Granada, 2006, pp. 613-623.

—. El Generalife, jardín del Paraíso, Granada, 2006.

-. "Genealogía del linaje Granada Venegas desde Yusuf IV, rey de Granada (1432), hasta la extinción de la varonía del linaje (1660)”, en GARCÍA LUJÁN, J.A. (ed.) Nobleza y Monarquía. Los linajes nobiliarios en el Reino de Granada, siglos XV-XIX. El linaje Granada Venegas, marqueses de Campotéjar, Huéscar, 2010, pp. 13-43.

—. Códice diplomático de la Casa de Campotéjar, Granada, 2009.

—. "Don Alonso de Granada Venegas Rengifo, cuarto señor de la Casa de Granada (1540-1611)", en prensa.

GARRIDO ATIENZA, M. Las capitulaciones para la entrega de Granada, Granada, 1910.

LÓPEZ NEVOT, J.A. "Los Granada Venegas, regidores, alguaciles mayores de Granada y procuradores de la ciudad en las Cortes de Castilla (siglos XVXVI)", en GARCÍA LUJÁN, J.A. (ed.) Nobleza y Monarquía. Los linajes nobiliarios en el Reino de Granada, siglos XV-XIX. El linaje Granada Venegas, marqueses de Campotéjar, Huéscar, 2010, pp. 325-360.

Fecha de recepción del artículo: mayo 2013

Fecha de aceptación y versión final: septiembre 2013 
